\title{
Magma Reservoir Beneath Azumayama Volcano, NE Japan as Inferred from Three-dimensional Electrical Resistivity Image by Magnetotellurics
}

Masahiro Ichiki ( $\sim$ ichiki@tohoku.ac.jp)

Graduate School of Science, Tohoku University https://orcid.org/0000-0003-0814-1265

Toshiki Kaida

Graduate School of Science, Tohoku University

Takashi Nakayama

Graduate School of Science, Tohoku University

Satoshi Miura

Graduate School of Science, Tohoku University

Mare Yamamoto

Graduate School of Science, Tohoku University

Yuichi Morita

Earthquake Research Institute, The University of Tokyo

Makoto Uyeshima

Earthquake Research Institute, The University of Tokyo

Full paper

Keywords: magnetotellurics, electrical resistivity, electrical conductivity, magma reservoir, melt fraction, permeability, percolation threshold, change point, hydrothermal fluid, Mogi source

Posted Date: January 7th, 2021

DOI: https://doi.org/10.21203/rs.3.rs-139301/v1

License: (a) (1) This work is licensed under a Creative Commons Attribution 4.0 International License. Read Full License

Version of Record: A version of this preprint was published at Earth, Planets and Space on July 27th, 2021. See the published version at https://doi.org/10.1186/s40623-021-01451-y. 


\section{Title}

2 Magma reservoir beneath Azumayama Volcano, NE Japan as inferred from three-

\section{3 dimensional electrical resistivity image by magnetotellurics}

4 Masahiro Ichiki, Research center for prediction of earthquakes and volcanic eruptions,

5 Graduate School of Science, Tohoku University, 6-6 Aoba, Aramaki, Aoba-ku, Sendai

6 980-8578, Japan, ichiki@tohoku.ac.jp

7 Toshiki Kaida, Research center for prediction of earthquakes and volcanic eruptions,

8 Graduate School of Science, Tohoku University, 6-6 Aoba, Aramaki, Aoba-ku, Sendai

9 980-8578, Japan, toshiki.kaida.a5@tohoku.ac.jp

10 Takashi Nakayama, Research center for prediction of earthquakes and volcanic eruptions,

11 Graduate School of Science, Tohoku University, 6-6 Aoba, Aramaki, Aoba-ku, Sendai

12 980-8578, Japan, takashi.nakayama.c8@tohoku.ac.jp

13 Satoshi Miura, Research center for prediction of earthquakes and volcanic eruptions,

14 Graduate School of Science, Tohoku University, 6-6 Aoba, Aramaki, Aoba-ku, Sendai

15 980-8578, Japan, miura3104@tohoku.ac.jp

16 Mare Yamamoto, Research center for prediction of earthquakes and volcanic eruptions, 
17 Graduate School of Science, Tohoku University, 6-6 Aoba, Aramaki, Aoba-ku, Sendai

18 980-8578, Japan, mare@tohoku.ac.jp

19 Yuichi Morira, Earthquake Research Institute, The University of Tokyo, 1-1-1 Yayoi,

20 Bunkyo-ku, Tokyo 113-0032, Japan, morita@eri.u-tokyo.ac.jp

21 Makoto Uyeshima, Earthquake Research Institute, The University of Tokyo, 1-1-1 Yayoi,

22 Bunkyo-ku, Tokyo 113-0032, Japan, uyeshima@eri.u-tokyo.ac.jp

\section{Corresponding author}

24 Masahiro Ichiki, Research center for prediction of earthquakes and volcanic eruptions,

25 Graduate School of Science, Tohoku University, 6-6 Aoba, Aramaki, Aoba-ku, Sendai

26 980-8578, Japan, ichiki@tohoku.ac.jp

27 


\section{Abstract}

29 An electrical resistivity image beneath Azumayama Volcano, NE Japan is modeled using

30 magnetotellurics to probe the magma/hydrothermal fluid distribution. The 3-D inversion

31 modeling images the conductive magma reservoir beneath Oana crater at depths of 3-15

$32 \mathrm{~km}$. The resolution scale for the conductor is $5 \mathrm{~km}$ by checkerboard resolution tests and

33 the $67 \%$ and $90 \%$ confidential intervals of resistivity are $0.2-5 \Omega \mathrm{m}$ and $0.02-70 \Omega \mathrm{m}$,

34 respectively, for the region of less than $3 \Omega \mathrm{m}$ resistivity. The shallower part of the

35 conductor is not explained by a water-saturated (5.5 wt \%) dacitic melt, and the more

36 probable interpretation is that it consists of a water-saturated, dacitic melt-silicic rock-

37 hydrothermal fluid complex. The deeper part of the conductor is interpreted as a water-

38 saturated (8 wt \%) andesitic melt-mafic rock complex. The Mogi inflation source

39 determined from GNSS and tilt data is located near the top boundary of the conductor at

40 a depth of 2.7-3.7 km, which suggests that the ascent of hydrothermal fluids exsolved

41 from the dacitic melt is interrupted by the impermeable wall and conduit. Assuming two

42 phases of hydrothermal fluid and silicic rock, the resistivity at the inflation source,

43 regarded as the upper bound resistivity of the conductor, is realized by the hydrothermal

44 fluid fraction below the percolation threshold porosity in an effusive eruption. This 
45 indicates that the percolation threshold porosity in an effusive eruption characterizes the

46 impermeable wall and conduit associated with the Mogi inflation source.

\section{Keywords}

48 magnetotellurics, electrical resistivity, electrical conductivity, magma reservoir, melt

49 fraction, permeability, percolation threshold, change point, hydrothermal fluid, Mogi

50 source 


\section{Main Text}

\section{1. Introduction}

54 Great earthquakes have often triggered eruptions in neighboring volcanoes

55 (Nishimura, 2017; Koyama, 2015; Bebbington \& Marzocchi, 2011). After the 2011

56 Tohoku-Oki Earthquake, the seismicities of deep low-frequency tremor and of volcano-

57 tectonic earthquake have turned active beneath a few volcanoes in northeastern (NE)

58 Japan (e.g. Ikegaya \& Yamamoto, 2020; Yamamoto, 2014). The potential eruptions of

59 these volcanoes have raised concerns, with the Azumayama Volcano being one of the

60 most concerning of the active volcanoes in NE Japan. Azumayama is located in the Nasu

61 volcanic chain of the Quarternary volcanic front in NE Japan (Takahashi et al., 2013;

62 Yamamoto, 2005), and is composed of several andesitic edifices that have emerged since

63 the Pleistocene (Figure 1). Oana crater in the eastern part of Azumayama has active

64 fumaroles with recent maximum effusion rates of 600 tons/day. Oana crater brought on

65 the recent phreatic eruptions in 1977, 1952, and 1950 (Japan Meteorological Agency,

66 2013). Spontaneous seismic swarms have been reported beneath Azumayama since 2000,

67 and geodetic data of the global navigation satellite system (GNSS) baseline extensions 
and of tilt changes accompanied those seismic swarms (Seki et al., 2020; Japan

69 Meteorological Agency, 2013; Yoshida et al., 2012). Although outstanding seismic

70 swarms were observed during 2014-2015 and 2018-2019 (Seki et al., 2020; Yoshigai et

71 al., 2019), no eruption has taken place so far.

72 For the eruption forecast, the shallower part beneath Azumayama down to a depth

73 of $0 \mathrm{~km}$ below sea level (depth is represented below sea level hereafter) is well

74 investigated (Seki et al., 2020; Yoshida et al., 2012). However, the transport and

75 distribution of magma/hydrothermal fluid in the $0-20 \mathrm{~km}$ depth range are unknown. This

76 depth range coincides with a seismicity gap: the volcano-tectonic earthquakes are

77 primarily restricted to depths of less than $1 \mathrm{~km}$, and deep low-frequency tremors occur

78 below $20 \mathrm{~km}$ depth (Japan Meteorological Agency, 2013). Furthermore, magma

79 reservoirs beneath active volcanoes generally lie at depths of a few to $10 \mathrm{~km}$ (Chaussard

80 \& Amelung, 2014), and any existing magma reservoir beneath Azumayama presumably

81 lies within this depth range. Takada \& Fukushima (2013) model the low-viscosity ellipse

82 beneath Azumayama at - $0.7-5.8 \mathrm{~km}$ depths from analysis of the interferometric synthetic

83 aperture radar (InSAR) data recording the subsidence of the edifice caused by the 2011 
84 Tohoku-Oki Earthquake. Chen et al. (2018) image the slow shear wave velocity (Vs)

85 region at depths of 0 to $10 \mathrm{~km}$ around Azumayama using ambient noise tomography.

86 Those studies provide broad and blurred images of the magma reservoir. Geodetic data

87 locate the Mogi inflation sources at depths of 3 and $9 \mathrm{~km}$ beneath Oana crater (Seki et al.,

88 2020). The Mogi inflation sources probably show a more precise outline of the magma

89 reservoir.

90 Electrical resistivity (the reciprocal of conductivity) models beneath active

91 volcanoes using magnetotellurics (MT) have succeeded in exposing clear images of

92 magma reservoirs (Hata et al., 2018; Cordell et al., 2018; Aizawa et al., 2014; Bertland et

93 al., 2012; Heise et al., 2010; Hill et al., 2009). The primary purpose of this study is to

94 model the three-dimensional (3-D) resistivity distribution below Azumayama down to 20

$95 \mathrm{~km}$ depth by MT, and we show the resultant resistivity model provides a clear image of

96 the magma reservoir beneath Azumayama. Along with defining the magma reservoir

97 from resistivity model, we discuss the petrological interpretation for the magma reservoir

98 and the threshold of a phreatic eruption of Azumayama.

99 The melt fraction and melt water content of magma reservoirs have been estimated 
100 from resistivity models based on laboratory data of melt and rock resistivity (Laumonier

101 et al., 2017, 2015; Guo et al., 2017; Heise et al., 2016; Ichiki et al., 2015; McGary et al.,

102 2014). To gain more reliable quantitative interpretation of the magma reservoir, we

103 perform checker board resolution tests (CRTs) to estimate a confidence interval of

104 resistivity (CIR) of the magma reservoir image. This contributes to a more rigorous

105 quantitative interpretation of the magma reservoir in the petrological contexts from the

106 laboratory data.

107 Hydrothermal fluids exsolve from melts in the magma reservoir, and the ascent of

108 hydrothermal fluids often triggers phreatic eruptions. A key parameter controlling the

109 eruption triggering is permeability along the hydrothermal fluid pathway. At shallow

110 depths down to several hundred meters below the surface, clay minerals likely constitute

111 the primary impermeable layers suppressing the ascent of hydrothermal fluids. The

112 impermeable clay layers are imaged by MT as conductive bodies (Matsunaga et al., 2020;

113 Yoshimura et al., 2018; Tsukamoto et al., 2018; Komori et al., 2013). On the other hand,

114 densified magma on the pathway probably plays the impermeable role at higher

115 temperatures and deeper depths (Colombier et al., 2017; Kushnir et al., 2016; Heap et al., 
116 2015; Okumura \& Sasaki, 2014). This study assumes this concept in which the densified

117 magma interrupts the ascent of hydrothermal fluids. The reduction of porosity and the

118 low hydrothermal fluid fraction resulting from the densification process produces a more

119 resistive image than the conductive hydrothermal fluids underlying the densified magma.

120 Although the theoretical relationship between the Kozeny-Carman equation

121 (permeability) and Archie's Law (resistivity) in porous media suggests that resistivity can

122 be converted into permeability, simple applications of the relationship are usually

123 misleading (Wright et al., 2009). Thus we estimate porosity (hydrothermal fluid fraction),

124 rather than permeability, of the impermeable region imaged as being resistive in

125 accordance with another relationship between resistivity and porosity, Hashin-

126 Shtrickman bound (Hashin \& Shtrickman, 1962). On the basis of the estimated porosity

127 of the impermeable region, we test which index characterizes the impermeable region,

128 percolation threshold (e.g. Burgisser et al., 2017; Blower, 2001) or "change point" in

129 porosity-permeability relationship (Kushnir et al., 2016;Farquharson et al., 2015; Heap et

130 al., 2015, 2014). The index may be used as a potential diagnostic threshold for the forecast

131 of a phreatic eruption of Azumayama. 


\section{2. Methods, Data, and Analyses}

\section{2.1. Basic concept of method, data and data processing}

134 MT and geomagnetic depth sounding (GDS) are resistivity exploration methods that

135 use the frequency response of electromagnetic (EM) field variation observed around the

136 Earth's surface. The frequency response varies with EM induction in the Earth induced

137 by external EM field variation. The frequency response and the EM induction reflect the

138 distribution of subsurface electrical resistivity. MT and GDS frequency responses, which

139 are impedance tensor and geomagnetic transfer functions, are defined as follows:

140

where $Z_{i j}(i, j=x, y)$ : impedance tensor, A, B: geomagnetic transfer function, $E_{i}(i=x, y)$,

$143 H_{i}(i=x, y, z)$ : Fourier spectrum of electric and magnetic field variation, subscript $x, y, z$ :

north-south (N-S), east-west (E-W), down-up component, $(f)$ : function of frequency. The

impedance tensor contains galvanic distortion, a kind of observational site effect, which

affects the direct interpretation of raw observed impedance. The galvanic distortion is

expressed as:

$$
\text { (3) }\left[\begin{array}{ll}
Z_{x x}^{o b s}(f) & Z_{x y}^{o b s}(f) \\
Z_{y x}^{o b s}(f) & Z_{y y}^{o b s}(f)
\end{array}\right]=\left[\begin{array}{ll}
C_{x x} & C_{x y} \\
C_{y x} & C_{y y}
\end{array}\right]\left[\begin{array}{ll}
Z_{x x}^{\text {inductive }}(f) & Z_{x y}^{\text {inductive }}(f) \\
Z_{y x}^{\text {inductive }}(f) & Z_{y y}^{\text {inductive }}(f)
\end{array}\right]
$$


$149 C_{i j}(i=x, y)$ is galvanic distortion tensor. Note that $C_{i j}$ is real and independent of frequency.

150 The distortion tensor cannot be fully corrected without performing additional,

151 cumbersome observations. Some researchers impose the correction by assuming spatial

152 smoothness or other constraints on the distortion tensor (Avdeeva et al., 2015). To cope

153 with the galvanic distortion, Caldwell et al. (2004) developed a distortion-free MT

154 parameter, the phase tensor, $\boldsymbol{\Phi}$ :

(4) $\boldsymbol{\Phi}=\boldsymbol{X}^{-1} \boldsymbol{Y}=\left[\begin{array}{ll}\Phi_{x x} & \Phi_{x y} \\ \Phi_{y x} & \Phi_{y y}\end{array}\right]$

(5) $\left[\begin{array}{ll}Z_{x x}^{o b s}(f) & Z_{x y}^{o b s}(f) \\ Z_{y x}^{o b s}(f) & Z_{y y}^{o b s}(f)\end{array}\right]=\left[\begin{array}{ll}X_{x x}(f) & X_{x y}(f) \\ X_{y x}(f) & X_{y y}(f)\end{array}\right]+i m\left[\begin{array}{ll}Y_{x x}(f) & Y_{x y}(f) \\ Y_{y x}(f) & Y_{y y}(f)\end{array}\right]=\boldsymbol{X}+i m \boldsymbol{Y}$

157 where superscript -1 : inverse matrix, im: imaginary number. The phase tensor indicates

158 the degree of subsurface resistivity heterogeneity (dimensionality) and the distortion-free,

159 equivalent one-dimensional (1-D) MT phase response. The phase tensor is diagonalized

160 to determine its principal axis using the horizontal axis rotation matrix, $\boldsymbol{R}$ :

161

(6) $\boldsymbol{\Phi}=\boldsymbol{R}^{T}(\alpha-\beta) \boldsymbol{\Phi}_{\text {min_max }} \boldsymbol{R}(\alpha+\beta)$

163

$$
=\left[\begin{array}{cc}
\cos (\alpha-\beta) & -\sin (\alpha-\beta) \\
\sin (\alpha-\beta) & \cos (\alpha-\beta)
\end{array}\right]\left[\begin{array}{cc}
\Phi_{\max } & 0 \\
0 & \Phi_{\min }
\end{array}\right]\left[\begin{array}{cc}
\cos (\alpha+\beta) & \sin (\alpha+\beta) \\
-\sin (\alpha+\beta) & \cos (\alpha+\beta)
\end{array}\right]
$$

(7) $\quad \alpha=1 / 2 \tan ^{-1}\left(\left(\Phi_{x y}+\Phi_{y x}\right) /\left(\Phi_{x x}-\Phi_{y y}\right)\right)$

164

(8) $\beta=1 / 2 \tan ^{-1}\left(\left(\Phi_{x y}-\Phi_{y x}\right) /\left(\Phi_{x x}+\Phi_{y y}\right)\right)$ 
Phase tensor ellipticity, $\Lambda$, is defined as:

166

(9) $\quad \Lambda=\left(\Phi_{\max }-\Phi_{\min }\right) /\left(\Phi_{\max }+\Phi_{\min }\right)$

167 The phase tensor is graphically represented by tensor ellipse (Heise et al., 2006). The

168 tensor principal axis represents eigenvalue and eigenvector, that is, tensor character

169 changes only in amplitude along the principal axis direction. Thus, the principal axis of

170 the phase tensor ellipse means that phase tensor element information in this direction is

171 not contaminated with information from other directions. Accordingly, the phase tensor

172 ellipse is represented by a circle $\left(\Phi_{\max }=\Phi_{\min }\right)$ in 1-D, an elliptical shape $\left(\Phi_{\max } \neq \Phi_{\min }\right)$ and

$173 \beta=0$ in two-dimensions (2-D), and an ellipse and $\beta \neq 0$ in 3-D. The arc tangent of the

174 square root of the phase tensor determinant is considered to be the distortion-free

175 equivalent 1-D MT phase response around an observation site. The square root of phase

176 tensor determinant is denoted as $\Phi_{2}$ :

177

(10) $\Phi_{2}=\sqrt{\Phi_{x x} \Phi_{y y}-\Phi_{x y} \Phi_{y x}}=\sqrt{\Phi_{\max } \Phi_{\min }}$

178 GDS data are graphically represented by an induction vector. The Parkinson vector,

179 which is the most commonly used induction vector, points towards the conductor: 
where $\boldsymbol{e}_{N}, \boldsymbol{e}_{E}$ represents northward and eastward unit vector, respectively. recorded five-component EM field variations. The two-component horizontal telluric

189 field was observed using $\mathrm{Pb}-\mathrm{PbCl}_{2}$ electrodes with $40 \mathrm{~m}$ dipole lengths. The three-

190 component magnetic field for remote-reference processing was recorded at Okura village,

191 Yamagata prefecture (about $97 \mathrm{~km}$ north of Mt. Issaikyo) using the ADU-07 system, and

192 at Nishiwaga town, Iwate prefecture (about $210 \mathrm{~km}$ NNE of Mt. Issaikyo) using the MTU-

193 5A system. The MT and GDS frequency responses of the two sites were calculated from

1940.00055 to $320 \mathrm{~Hz}$ using SSMT2K and MTEDITOR (Phoenix Geophysics), and for the

195 other 16 sites from 0.00012 to $384 \mathrm{~Hz}$ using BIRRP code (Chave \& Thomson, 2004).

196 2.2. Three-dimensional resistivity modeling

197 The WSINV3DMT inversion code (Siripunvaraporn \& Egbert, 2009) is used to 
model the distribution of 3-D resistivity beneath Azumayama. The WSINV3DMT code seeks an optimal model by minimizing the following objective function, $W$, using

200 Occam inversion algorithm (Constable et al., 1987):

$202 \boldsymbol{m}$ : model parameter vector, $\boldsymbol{m}_{\boldsymbol{0}}$ : prior model parameter vector (fixed in iteration), $\boldsymbol{C}_{\boldsymbol{m}}$ :

203 model covariance matrix, $\boldsymbol{d}$ : data vector, $\boldsymbol{C}_{\boldsymbol{d}}$ : data covariance matrix, $\boldsymbol{F}[\mathrm{]}$ : 3 -D forward

204 operator, $\lambda$ : Lagrange multiplier. The first and second terms are regularization and data

205 misfit, respectively. The $\lambda$ is determined at each iteration stage so the normalized root-

206 mean-squared (RMS) misfit takes a minimum value. We call this Occam process. The

207 inversion data are real and imaginary parts of the MT impedance and GDS response at

20818 periods, which have octaves between 1024 , and $1.5625 \times 10^{-2}$, and $1.0417 \times 10^{-2}$

209 seconds. The number of data points is 3888 (18 sites $\times 18$ periods $\times 12$ responses $)$. We

210 give $5 \%$ of the MT impedance and $10 \%$ of the GDS response data to the error floor. The

211 modeling space is $420 \mathrm{~km} \times 417 \mathrm{~km} \times 150 \mathrm{~km}$, which is divided into $57 \times 59 \times 64$ blocks

212 in N-S, E-W and vertical directions. Resistivity of blocks in the marine area is fixed at

$2130.3333 \Omega \mathrm{m}$ and the SRTM30_PLUS model (Becker et al., 2009) is used to distinguish 
217 vertical direction (Siripunvaraporn et al., 2005). The relaxation parameter $4 \delta \tau$ (op. cit.) is

218 fixed at 2.0 in all three directions.

221 given maximum iteration times. The RMS misfit of all data is defined as:

$$
\text { (14) RMS misfit }=\sqrt{\frac{1}{N}(\boldsymbol{d}-\boldsymbol{F}[\boldsymbol{m}])^{T} \boldsymbol{C}_{\boldsymbol{d}}^{-1}(\boldsymbol{d}-\boldsymbol{F}[\boldsymbol{m}])}
$$

where $N$ is number of data. The RMS misfit threshold and the maximum iteration times are set to 1.0 and 10 , respectively. subsurface region is uniform, respectively. We test the four initial prior models, of which

227 the subsurface resistivities are $100,300,1000$, and $3000 \Omega \mathrm{m}$. If one inversion operation completes in case where the RMS misfit achieved 1.0, the solution is accepted as a final 
230 achieving the desired RMS, we replace the prior model into the best solution giving a

231 minimum RMS misfit during the inversion operation (denoted as prior model update),

232 and repeat another inversion operation. Once the best data misfit during the inversion

233 operation do not significantly decrease compared with that during the previous inversion

234 operation, the inversion stops and the solution is accepted as a final model. The F-test is

235 employed to judge whether the data misfit significantly decreases or not. The test statistic

$236 F$, defined below, follows an F-distribution with the degree of freedom (DOF) $N$ and $N$ :

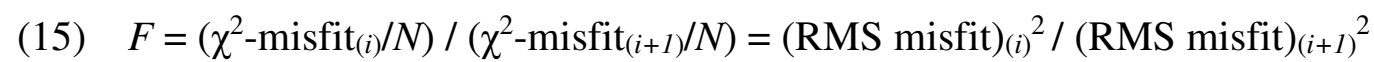

238 where subscript $i$ and $i+1$ means $i$-th and $(i+1)$-th prior model update. The $\chi^{2}$-misfit in

239 Equation 15 is defined as:

240

(16) $\quad \chi^{2}$-misfit $=(\boldsymbol{d}-\boldsymbol{F}[\boldsymbol{m}])^{\mathrm{T}} \boldsymbol{C}_{\mathrm{d}}^{-1}(\boldsymbol{d}-\boldsymbol{F}[\boldsymbol{m}])=N \times(\mathrm{RMS} \text { misfit })^{2}$

241 We adopt the threshold 1.054, the $95 \%$ confidence level of the left-tailed (or $5 \%$ significance level of the right-tailed) F-test with DOF 3888 and 3888. originated from each of the four initial prior models. 
246 between two phase tensors. Two kinds of misfit phase tensor have been proposed: one by

247 Peacock et al. (2012) and the other by Heise et al. (2007, 2008), and this study uses the

248 misfit phase tensor of Peacock et al (2012). The misfit phase tensor of Peacock et al.

249 (2012), $\Delta \boldsymbol{\Phi}_{\text {Peacock }}$, and the misfit of the arithmetic mean of two principal axis magnitudes,

$250 \Delta \Phi_{\text {principal }}$ are:

251

(17) $\Delta \boldsymbol{\Phi}_{\text {Peacock }}=\boldsymbol{E}-\left(\boldsymbol{\Phi}_{\text {obs }}^{-1} \boldsymbol{\Phi}_{\text {cal }}\right)$

253 where $\boldsymbol{E}: 2 \times 2$ unit matrix, $\boldsymbol{\Phi}_{\text {obs }}$ : observed phase tensor, $\boldsymbol{\Phi}_{\text {cal }}$ : phase tensor calculated

254 from resistivity model, $\Phi_{\max }^{o b s}, \Phi_{\min }{ }^{o b s}$ : two principal axis magnitudes of $\boldsymbol{\Phi}_{o b s}, \Phi_{\max }^{c a l}$,

$255 \Phi_{\min }{ }^{c a l}$ : two principal axis magnitudes of $\boldsymbol{\Phi}_{c a l}, \delta \Phi_{\max }, \delta \Phi_{\min }$ : standard errors of two

256 principal axis magnitudes of $\boldsymbol{\Phi}_{o b s}$. Misfit phase tensor is graphically drawn in the same

257 manner as a phase tensor. However, when an observed phase tensor has a large ellipticity,

258 a large maximum principal axis often remains in both the Peacock et al.'s and Heise et

259 al.'s misfit phase tensor ellipses, even if the data fit is fairly good. The reason we use

260 Peacock et al.'s misfit phase tensor ellipse is the straightforward nature, that is, the

maximum principal axis azimuth approaches $\alpha_{o b s}+\beta_{o b s}+\pi / 2$ in a large ellipticity case as 
complex nature. We explain the detail in supplemental material 1.

\section{3. Results}

265 Figure 2 shows the observed $\tan ^{-1}\left(\Phi_{2}\right)$ at various frequencies or periods. The $\tan ^{-}$

$26{ }^{1}\left(\Phi_{2}\right)$ in the frequency range higher than $8.0 \mathrm{~Hz}$ has higher values in the area east of Oana

267 crater. The high $\tan ^{-1}\left(\Phi_{2}\right)$ area assumes E-W elongation towards Oana crater. The $\tan ^{-}$

$268{ }^{1}\left(\Phi_{2}\right)$ distribution typically shows N-S trends in the period range longer than $8.0 \mathrm{~s}$, and

269 the $\tan ^{-1}\left(\Phi_{2}\right)$ greater than $45^{\circ}$ dominates in the western part of the area. The $\tan ^{-1}\left(\Phi_{2}\right)$ falls

270 below $45^{\circ}$ across the study area at 512 s period. These findings are consistent with the

271 final inversion resistivity model.

273 in all inversion operations do not achieve 1.0. We obtain the final resistivity model at the

274 third prior model update starting with the initial prior model of $1000 \Omega \mathrm{m}$ subsurface. The

275 best RMS misfit is 2.42 .

Figures 4 to 6 represent the results of the final resistivity model in plan or map view,

277 as a series of vertical profiles in the E-W direction, and as a similar series of vertical 
278 profiles in the N-S direction. Figure 4 indicates the presence of three thin conductive

279 patches in the eastern part from Oana crater at a depth of $0.05 \mathrm{~km}$. Those conductive

280 patches fade with increasing depth, and the E-W elongated conductor appears beneath

281 Oana crater at $3.50 \mathrm{~km}$ depth. The E-W elongated conductive feature extends down to a

282 depth of $5.50 \mathrm{~km}$. The structure is delineated by the convex shape of the conductor in 3.5-

$2835.5 \mathrm{~km}$ depth range in the $C$ - $C^{\prime}$ profile of Figure 5 . The $\Phi_{2}$ response distribution in the

284 high frequency range $(>8.0 \mathrm{~Hz})$ of the final resistivity model (Figure 2 ) also reveals this

285 feature. The conductor beneath Oana crater expands in the N-S direction at depths below

$286 \quad 6 \mathrm{~km}$. The plan view at $7.5 \mathrm{~km}$ depth in Figure 4 and the $H-H^{\prime}$ profile in Figure 6 provide

287 clear images of the expansion. The $\Phi_{2}$ distribution also shows this N-S trend at the middle

288 periods of 8.0 and $64 \mathrm{~s}$ (Figure 2). The area in the 7-9 $\mathrm{km}$ depth range below Oana crater

289 has the lowest resistivity value $(\sim 0.1 \Omega \mathrm{m})$ in the final model, which also shows a second

290 conductive block between 5 and $10 \mathrm{~km}$ depth beneath Naka-azuma. The twin conductor

291 image can be found in the plan views at 7.50 and $9.50 \mathrm{~km}$ depth of Figure 4 and in the $D$ -

$292 D^{\prime}$ profile of Figure 5. No apparent conductor is found below the observation sites at

293 depths greater than $20 \mathrm{~km}$. 
295 ellipses. The phase tensor ellipses across the study area have a large ellipticity in the

296 observed period bands. Because the phase tensor ellipticity is so great, some large

297 maximum principal axes remain for the misfit phase tensors. However, over half of these

298 align to the azimuth of $\alpha_{o b s}+\beta_{o b s}+\pi / 2$. The data fits are reasonable in the middle period

299 range between $64 \mathrm{~s}$ and $32 \mathrm{~Hz}$, while the misfit phase tensor ellipses show a poor data fit

300 at the $512 \mathrm{~s}$ period or longer. Details on the data fitting of MT apparent resistivity, phase

301 responses, and Parkinson vectors are presented in supplemental material 2.

\section{4. Resolution and Confidence Interval of Resistivity}

303 The better data misfit in the middle period range of 8-64 s indicates that the

304 conductive region at 3-15 km depth is well resolved. Focusing the conductor, we perform

305 the CRTs to investigate the resolution of the conductor on this observation condition, and

306 estimate CIR of the conductor.

Two CRTs are demonstrated, here. Figures 8-10 show the two checkerboard models

used to test whether the final model has 3 or $5 \mathrm{~km}$ resolution. The checkerboard is a single 
marine and air blocks are fixed, as described in subsection 2.2. Synthetic datasets are

311 generated of the respective components at each site that are composed of MT impedance

312 and geomagnetic transfer functions with $5 \%$ amplitude Gaussian noises. Because a

313 substantial amount of time and effort are required to demonstrate CRT replicating the

314 precise Occam process of the final model, the Lagrange multiplier, $\lambda$ in Equation 13, is

315 fixed constant in the CRTs. The $\lambda$ takes 0.10 at iteration 9 on the initial prior model, 0.10

316 at iteration 8 on the first update prior model, 0.032 at iteration 5 on the second update,

317 and 10 at iteration 2 on the third update, until we achieve the final model (cf. blue plots

318 in Figure 3). Here, we fix $\lambda$ at 0.10 in the CRTs.

319 Figures 8 and 10 show the results of CRT using checkerboxes with dimensions of

320 about $3 \mathrm{~km}$ to a side. Outputs using each prior model shows blurred checkerboxes, and

321 the number of conductive checkerboxes cannot be properly determined. The northeastern

most output conductive checkerbox moves horizontally from the original position, and 
326 the five conductive checkerboxes could be distinguished. Moreover, the conductive

327 checkerbox resistivities are properly estimated to be $1 \Omega \mathrm{m}$ at the third update of the prior

328 model. The eight conductive checkerboxes at depth outside the observation network are

329 hardly recognizable. These two CRTs reveal that the conductor at 5-10 km depth has no

330 resolution with the scale of less than $3 \mathrm{~km}$, but reasonable resolution with the scale of

331 over $5 \mathrm{~km}$.

332 We estimate the CIR of the conductor. The area of the conductor is defined as that

333 where the resistivity is less than 3 or $1 \Omega \mathrm{m}$ between 3 and $15 \mathrm{~km}$ depth in the final model

334 (Figure 11). The horizontal dimension of the defined area is $15 \times 20 \mathrm{~km}$ or $5 \times 10 \mathrm{~km}$.

335 The target area's resistivity is changed to a variety of constant values between 0.01 and

$336100 \Omega \mathrm{m}$, and the forward modeling is repeated to chase the data misfit change of each

337 site.

338

Figure 12 shows the F-statistics defined as Equation 15 for each of the 18 sites. Note that total RMS misfit using all sites show no significant change in terms of the target area's resistivity. The 95, 90, and $67 \%$ confidence levels of left-tailed F-test with DOF

341216 and $216(18$ periods $\times 12$ responses per site) are $1.252,1.191$, and 1.062 respectively. 
342 As a result, the 90 and $67 \%$ CIR of the under $3 \Omega \mathrm{m}$ area are estimated to be $0.02 \leqq$

$343(90 \% \mathrm{CIR}) \leqq 70 \Omega \mathrm{m}$ and $0.3 \leqq(67 \% \mathrm{CIR}) \leqq 5 \Omega \mathrm{m}$ (Figure $12 \mathrm{a})$. The RMS misfits

344 of some sites get significantly worse as the target area's resistivity decrease. The same

345 behavior also appears as the target area's resistivity increases. This nature enables both

346 the upper and lower bounds of CIR to be constrained. On the other hand, the CIR of the

347 area under $1 \Omega \mathrm{m}$ cannot be constrained using any of the 95,90 and $67 \%$ confidence

348 levels (Figure 12b). This is presumably due to the insufficient volume of the target area.

349 The integral equation formulation for the 3-D EM induction problem states that the

350 product of conductivity perturbation and volume, and distance between conductivity

351 perturbation (source) and a site (receiver) primarily controls the EM field and impedance

352 response changes at the site (Hohman, 1975; Wannamaker et al., 1984; Zhdanov et al.,

353 2006). Note that less distance between the source and the receiver produces larger Green

354 functions of EM fields.

\section{5. Discussion}

356 5.1. Comparisons with other geophysical results and other active volcanoes

357 The conductive image at the $3-15 \mathrm{~km}$ depth range is consistent with the slow Vs

358 region by ambient noise tomography (Chen et al., 2018), although the core of the slow 
velocity region is located several $\mathrm{km}$ to the west. The low viscosity ellipsoid body inferred model gives a more focused image than the slow velocity and low viscosity models. volcanic activities have revealed the presence of the Mogi inflation source deeper than 2

$366 \mathrm{~km}$ beneath Oana crater. Seki et al. (2020) propose the two and three Mogi inflation

367 source models by analyzing the data of the tilt meter located about $800 \mathrm{~m}$ ESE of Oana 368 crater and 16 GNSS sites during the volcanic activity in May 2018 to April 2019. Figure

36913 shows the Mogi model inflation source models superimposed on the final resistivity model. The inflation source at 2.7 or $3.7 \mathrm{~km}$ depth lies in the resistive side near the top boundary of the conductor. The resistivity around the inflation source is $30-300 \Omega \mathrm{m}$.

372 Although it is hard to evaluate the CIR of the area around the inflation source, the lower

373 bound of the CIR could be taken as the upper bound of the CIR of the conductor estimated

374 in the previous section. On the other hand, the source at $9 \mathrm{~km}$ depth from the Mogi 
375 inflation source model is located inside the conductor. However, this Mogi source

376 location is determined with an accuracy of a few $\mathrm{km}$. This Mogi source likely becomes

377 compressive occasionally. The tilt meter located about $11 \mathrm{~km}$ south of Oana crater

378 showed a declining trend in the direction toward Oana crater during the volcanic tremors

379 on 22 July, 2019 (Yoshigai et al., 2019). The compression source of the tilt change is

380 located at about $10 \mathrm{~km}$ depth beneath Oana crater (Yoshigai and Nihara, priv. comm.),

381 which likely coincides with the inflation source at $9 \mathrm{~km}$ depth of the three Mogi inflation

382 source model.

383 Similar conductors beneath other active volcanoes are found at depths of 3-15 km

384 (e.g. Aso: Hata et al., 2018; Laguna del Maule: Cordell et al., 2018; Kirishima: Aizawa

385 et al., 2014; Taupo: Bertland et al., 2012, Heise et al., 2010; Mt. Adams and St. Helens:

386 Hill et al., 2009). Melt inclusion samples from active volcanoes show that magma

387 reservoirs generally lie at depth ranges of a few $\mathrm{km}$ to $13 \mathrm{~km}$ (Cashman et al., 2017).

388 According to the compilation by Chaussard \& Amelung (2014), magma reservoir depths

389 in arc volcanoes are a few to $10 \mathrm{~km}$ deep, and correlate with crustal thickness and age.

390 Thus, the conductor beneath Oana crater is interpreted as the magma reservoir comprising 
magma, hydrothermal fluid, and rock complexes.

$392 \quad$ 5.2. Melt fraction of the magma reservoir

393 We interpret that the shallower part of the conductor or the magma reservoir (down

394 to 4 or $5 \mathrm{~km}$ ) is composed of dacitic melt-rock-hydrothermal fluid complex. Geothermal

395 gradients of over 75-100 K/km around Azumayama (Tanaka et al., 2004) indicate

396 geotherms above the solidus of silicic melts at greater depths than 4 or $5 \mathrm{~km}$, and melts

397 may exist in the magma reservoir. The phenocrysts in the andesite and basaltic andesite

398 samples of Oana unit are divided into mafic, mixed magma-derived, and felsic silicates

399 (Ban et al., 2016). The felsic phenocrysts have the shallowest origin, which is dacitic melt

400 with water contents of 2.75-3.25 wt \% at about $4 \mathrm{~km}$ depth by Rhyolite-MELTS analysis,

401 and at $880-890{ }^{\circ} \mathrm{C}$ by pyroxene geothermometry (op. cit.). The $4 \mathrm{~km}$ depth is near the top

402 of the conductor. Hence, we first assume the shallower part of the conductor is composed

403 of two phases of dacitic melt and rock. The melt water content can range up to the water

404 saturated condition of $5.5 \mathrm{wt} \%$ (Wallace, 2005; Sisson and Bacon, 1999). Based on recent

405 laboratory data of dacitic melt resistivity and modified Archie's Law with $m=1.05$

406 (Laumonier, et al., 2015), we calculate bulk resistivity for the dacitic melt and rock

407 complex at $900{ }^{\circ} \mathrm{C}$ and $4 \mathrm{~km}$ depth $(0.15 \mathrm{GPa})$. Figure 14 compares the bulk resistivity 
and the $67 \% \mathrm{CIR}(0.3$ to $5 \Omega \mathrm{m})$ at various water contents. While the upper bound of $67 \%$

409 CIR beneath Oana crater corresponds to the complex with a melt fraction of 0.22 to 0.63

410 at water contents of 5.5 to $3.5 \mathrm{wt} \%$, the complex with any reasonable melt and water

411 content cannot explain the lower bound of $67 \%$ CIR. Hydrothermal fluids and/or mafic

412 melts are more or less required to explain the lower bound of $67 \%$ CIR (see also

413 Laumonier et al., 2015). Regarding the shallower part of the magma reservoir where the

414 magma differentiation is mature, hydrothermal fluids rather than mafic melts are the

415 probable interpretation for this discrepancy.

416 Magma mixing and differentiation probably occur in the magma reservoir (e.g.

417 Takahashi et al., 2013; Yoshida et al., 2014; Tatsumi et al., 2008; Kimura \& Yoshida,

418 2006; Toya et al., 2005), and result in the magma reservoir becoming increasingly more

419 mafic with depth. Thus, we consider more mafic condition, an andesitic melt and rock

420 complex at a deep depth inside the conductor. Figure 15 shows the bulk resistivity of the complex at $900{ }^{\circ} \mathrm{C}$, and $9 \mathrm{~km}$ depth $(0.29 \mathrm{GPa})$, with the melt water contents up to 8 wt $\%$ of water saturation (op. cit.). The modified Archie's Law with $m=1.05$ is used with 

at water contents of 8.0 to $4.0 \mathrm{wt} \%$. The lower boundary corresponds to the complex with a melt fraction of 0.61 (Guo et al.'s model) or 0.84 (Laumonier et al.'s model) with

427 almost the water saturation. A melt with the water content lower than 8.0 wt \% cannot 428 explain the lower bound. Meanwhile, the Mogi inflation/compression source is likely 429 located in 9-10 $\mathrm{km}$ depth range. Although the accuracy of the Mogi source location is a 430 few km, we assume the Mogi source lies inside the conductor. The viscosity of a melt and 431 rock complex is a function of the melt fraction. The viscosity abruptly changes around 432 melt fractions of 0.4 . The complex with a melt fraction of less than 0.4 is defined as mush.

433 The deformation of mush is under the control of crystalline or solid framework rather

434 than that of melt (Cashman et al., 2017, and references herein). Hence, the Mogi source must lie in the mush, assuming that the Mogi source is located inside the magma reservoir.

436 The melt fraction of 0.4 and melt water content of $8 \mathrm{wt} \%$ results in 0.47 or $0.73 \Omega \mathrm{m}$,

437 which almost explains the lower bound of $67 \%$ CIR. Consequently, the magma reservoir's resistivity with $67 \%$ CIR may be explained by a water-saturated andesitic melt.

439 However, if we consider the safer $90 \%$, even higher pressure condition (the conductor 
bottom $\sim 15 \mathrm{~km}$ depth) and greater water content ( 10 wt \%) cannot explain the lower

441 bound $(0.02 \Omega \mathrm{m})$ of the $90 \% \mathrm{CIR}$.

\section{$442 \quad$ 5.3. Interruption of hydrothermal fluid ascent}

443 The shallower part of the magma reservoir is composed of the dacitic melt-rock-

444 hydrothermal fluid complex. Although hydrothermal fluids exsolve from the dacitic melt

445 near the top of the magma reservoir, an impermeable wall and conduit prevent the

446 hydrothermal fluids from ascending and causing a phreatic eruption. The Mogi inflation

447 source at 2.7 or $3.7 \mathrm{~km}$ depth near the top of the conductor indicates the spot of the

448 interruption. The impermeable wall and conduit results from porosity reduction through

449 magma densification (Heap et al., 2015; Okumura \& Sasaki, 2014). The densification

450 presumably has reached the percolation threshold in porosity (e.g. Burgisser et al., 2017;

451 Blower, 2001) or the "change point" porosity in the permeability-porosity relationship

452 (Heap et al., 2014, 2015; Farquharson et al., 2015; Kushnir et al., 2016). We test which

453 index gives the consistent explanation for the resistivity of the impermeable region,

454 percolation threshold or change point. The change point porosity is reported to be 10 to

45515 vol \% (op. cit.). On the other hand, the percolation threshold varies depending on the

456 conditions such as the transition between explosive and effusive eruptions, the inherent 
457 hysteresis between prograde and retrograde periods, and others (e.g. Burgisser et al.,

458 2017; Colombier et al. 2017; Rust \& Cashman 2011; Michaut et al., 2009; Muller, et al.,

459 2005; Rust \& Cashman, 2004). We consider the general percolation threshold for effusive

460 eruption, $5 \%$, and for explosive eruption, $30 \%$ (Colombier et al., 2017; Muller et al.,

461 2005). The impermeable region means the Mogi inflation source region at 2.7 or $3.7 \mathrm{~km}$

462 depth in this context. As mentioned in subsection 5.1, we take the lower bound of the CIR

463 at the Mogi inflation source as the upper bound of the CIR for the magma reservoir's

464 conductor.

Figure 16 shows the bulk resistivity of two phases (hydrothermal fluid-rock) as a

466 function of the hydrothermal fluid fraction. The Hashin-Shtrickman upper bound in

467 conductivity (Hashin \& Shtrickman, 1962) is used as mixing law, because of no

468 information about $m$ in modified Archie's Law on this two phase complex. The

469 hydrothermal fluid is assumed to be supercritical with a resistivity of 0.3 to $0.1 \Omega \mathrm{m}$ at

470 conditions of $750-900{ }^{\circ} \mathrm{C}, 0.13-0.15 \mathrm{GPa}$, and nearly saturated with $\mathrm{CO}_{2}$ exsolution

471 (Nesbitt, 1993; Marshall \& Frantz, 1987). Most combinations of the lower bound of CIR

472 and hydrothermal fluid resistivity suggest that the hydrothermal fluid fraction has less 
478 threshold for effusive eruption and below the change point. The change point porosity could be the threshold that characterizes the permeability causing the Mogi inflation 480 source.

\section{6. Conclusions}

482 Our 3-D resistivity model shows a clear conductive image of a magma reservoir

483 beneath Oana crater of Azumayama Volcano at depths of 3 to $15 \mathrm{~km}$. The horizontal

484 dimension of the less than $3 \Omega \mathrm{m}$ conductor is 15 to $20 \mathrm{~km}$. The $67 \%$ and $90 \% \mathrm{CIR}$ of 485 the conductor is 0.3 to 5 and 0.02 to $70 \Omega \mathrm{m}$, respectively. The confidence interval is 486 estimated by using a F-test to evaluate the RMS misfit change of each site with changes 487 in the conductor's resistivity. The CRTs suggest the dataset can resolve a conductive body over $5 \mathrm{~km}$ in scale with unbiased resistivity at depths of 5 to $10 \mathrm{~km}$. The image of the 
conductive magma reservoir by the final resistivity model overlapped with the low

490 viscosity model from InSAR data (Takada \& Fukushima, 2013) and the slow Vs region

491 determined by ambient noise tomography (Chen et al., 2018). The Mogi inflation sources

492 derived from GNSS and tilt data are located near the top boundary of the magma

493 reservoir's conductor at 2.7 or $3.7 \mathrm{~km}$ depth, and inside the conductor at $9 \mathrm{~km}$ depth. The

494 shallower part of the magma reservoir is interpreted as a water-saturated, dacitic melt-

495 silicic rock-hydrothermal fluid complex. The hydrothermal fluids appear necessary,

496 because the lower boundary of the confidence interval for resistivity cannot be explained

497 by a water-saturated (5.5 wt \%) dacitic melt alone. The deeper part of the conductor is

498 interpreted as a water-saturated (8 wt \%) andesitic melt-mafic rock complex. Assuming

499 that the Mogi inflation source at 2.7 or $3.7 \mathrm{~km}$ depth indicates the interruption of

500 hydrothermal fluid ascent, the porosity or hydrothermal fluid fraction at the Mogi

501 inflation source is estimated to be generally below $5 \%$ of the percolation threshold in the

502 effusive eruption case. Depending on the CIR at the Mogi inflation source and resistivity

503 of hydrothermal fluid, the change point of porosity-permeability, rather than the

504 percolation threshold, might characterize the permeability resulting in the Mogi source. 
506 between the conductor beneath Oana crater and deep, low-frequency tremors. This may 507 be due to the use of MT data in a period range shorter than 1024 s. Longer-period MT 508 data will probably reveal the lower crust conductor.

509 


\section{Declarations}

511 Ethics approval and consent to participate

$512 \quad$ Not applicable

513 Consent for publication

$514 \quad$ Not applicable

\section{$515 \quad$ List of abbreviations}

516 1-D, 2-D, 3-D: one-dimensional, two-dimensional, three-dimensional

$517 \quad$ CIR: confidence interval of resistivity

$518 \quad$ CRT: checkerboard resolution test

$519 \quad$ DOF: degree of freedom

$520 \quad$ EM: electromagnetic

$521 \quad$ GDS: geomagnetic depth soundings

522 GNSS: global navigation satellite system

523 InSAR: interferometric synthetic aperture radar

$524 \quad$ MT: magnetotellurics

525

NE, NNE: northeast(ern), north-north-east(ern)

526

N-S, E-W: north-south, east-west 
RMS: root-mean-squared

Vs: shear wave velocity

\section{Availability of data and materials} The data are available through corresponding author by request.

\section{Competing interests}

The authors have no competing interests.

\section{$533 \quad$ Funding}

534 This study is supported by the Ministry of Education, Culture, Sports, Science and

535 Technology (MEXT) of Japan, under the Program of Mobile and Intensive Observation-

536 Research System Integration for Volcanic Areas, and the Earthquake and Volcano

537 Hazards Observation and Research Program (Earthquake and Volcano Hazard Reduction

538 Research).

\section{$539 \quad$ Authors' contributions}

540 MI performed MT data acquisition, all analyses, discussion, wrote the manuscript

541 and created the figures. TK, TN performed MT data acquisition. SM, MY planned the

542 project. YM proposed the project and obtained funding. MU prepared and calibrated the 
543 magnetotelluric equipment, and contributed to the discussion.

\section{Acknowledgements}

545 We are grateful to Satoshi Okumura, Masao Ban, Yu Nihara, Yusuke Yoshigai, Jun

546 Okada, Yo Fukushima, and the staff of Sendai Regional Headquarters of Japan

547 Meteorological Agency for valuable comments and discussion. We thank Koki Aizawa

548 for providing the operation techniques of ADU-07e. Urabandai Environment Ranger

549 Office, Fukushima and Yonezawa City Office, and Fukushima and Aizu Forest Office

550 facilitated the observation. Geothermal Energy Research and Development Co. Ltd. and

551 Nittetsu Mining Consultants Co. Ltd. kindly provided the remote reference data. Figures

552 are created using Generic Mapping Tools and Paraview Software.

553 


\section{References}

555 Aizawa, K., et al., (2014), Three-dimensional resistivity structure and magma plumbing 556 system of the Kirishima Volcanoes as inferred from broadband magnetotelluric data, J.

557 Geophys. Res. Solid Earth, 119, 198-215, doi:10.1002/2013JB010682

558 Avdeeva, A., Moorkamp, M., Avdeev, D., Jegen, M., Miensopust, M., (2015), Three559 dimensional inversion of magnetotelluric impedance tensor data and full distortion matrix, 560 Geophys. J. Inter., 202, 464-481, doi: 10.1093/gji/ggv144

561 Ban, M., Takebe, Y., Adachi, T., Matsui, R., Nishi, Y., (2016), Eruption histories of Zao 562 and Azuma Volcanoes and their magma feeding systems for recent activities, Bull. Earthq.

563 Res. Inst., Univ. Tokyo, 91, 25-39

564 Bebbington, M. S., and Marzocchi, W., (2011), Stochastic models for earthquake 565 triggering of volcanic eruptions, J. Geophys. Res. Solid Earth, 116, B05204, 566 doi:10.1029/2010JB008114

567 Becker, J. J., et al., (2009), Global Bathymetry and Elevation Data at 30 Arc Seconds 568 Resolution: SRTM30_PLUS, Marine Geodesy, 32, 355-371, doi: $10.1080 / 01490410903297766$

570 Bertland, E. A., et al., (2012), Magnetotelluric imaging of upper-crustal convection 
571 plumes beneath the Taupo Volcanic Zone, New Zealand, Geophys. Res. Lett., 39, L02304,

\section{2 doi:10.1029/2011GL050177}

573 Blower, J., (2001), Factors controlling permeability-porosity relationships in magma.

574 Bull. Volcanol., 63, 497-504. doi: 10.1007/s004450100172

575 Burgisser, A., Chevalier, L., Gardner, J. E., Castro, J. M., (2017), The percolation

576 threshold and permeability evolution of ascending magmas, Earth Planet. Sci. Lett., 470,

577 37-47, doi: 10.1016/j.eps1.2017.04.023

578 Caldwell, T. G., Bibby, H. M., Brown, C., (2004), The magnetotelluric phase tensor,

579 Geophys. J. Inter., 158, 457-469, doi: 10.1111/j.1365-246X.2004.02281.x

580 Cashman, K. V., Sparks, R. S. J., Blundy, J. D., (2017), Vertically extensive and unstable

581 magmatic systems: A unified view of igneous processes, Science, 355, 6331, eaag3055,

582 doi: $10.1126 /$ science.aag3055

583 Chaussard, E., and Amelung, F., (2014), Regional controls on magma ascent and storage

584 in volcanic arcs, Geochem. Geophys. Geosyst., 15, 1407-1418, 585 doi:10.1002/2013GC005216

586 Chave, A. D., and Thomson, D. J., (2004), Bounded influence magnetotelluric response 
587 function estimation, Geophys. J. Inter., 157, 988-1006, doi:10.1111/j.1365-

588 246X.2004.02203.X

589 Chen, K.-X., Gung, Y., Kuo, B.-Y., Huang, T.-Y., (2018), Crustal magmatism and

590 deformation fabrics in northeast Japan revealed by ambient noise tomography. J. Geophys.

591 Res. Solid Earth, 123, 8891-8906, doi: 10.1029/2017JB015209

592 Colombier, M., et al., (2017), The evolution of pore connectivity in volcanic rocks, Earth

593 Planet. Sci. Lett., 462, 99-109, doi: 10.1016/j.epsl.2017.01.011

594 Constable, S. C., Parker, R. L., Constable, C. G., (1987), Occam's inversion; a practical

595 algorithm for generating smooth models from electromagnetic sounding data, Geophys.,

596 52, 289-300, doi: 10.1190/1.1442303

597 Cordell, D., Unsworth, M. J., Diaz, D., (2018), Imaging the Laguna del Maule volcanic

598 field, central Chile, using magnetotellurics: Evidence for crustal melt regions laterally-

599 offset from surface vents and Holocene lava flows. Earth Planet. Sci. Lett., 488, 168-180,

600 doi: $10.1016 /$ j.epsl.2018.01.007

601 Farquharson, J., Heap, M. J., Varley, N. R., Baud, P. Reuschle, T., (2015), Permeability

602 and porosity relationships of edifice-forming andesites: A combined field and laboratory 
603 study, J. Volcanol. Geotherm. Res., 297, 52-68, doi:10.1016/j.jvolgeores.2015.03.016

604 Guo, X., Li, B., Ni, H., Mao, Z., (2017), Electrical conductivity of hydrous andesitic melts

605 pertinent to subduction zones, J. Geophys. Res. Solid Earth, 122, 1777-1788,

606 doi:10.1002/2016JB013524

607 Hashin, Z., and Shtrikman, S., (1962), A variational approach to the theory of effective

608 magnetic permeability of multiphase materials: J. Appl. Phys., 33 (10), 3125-3131, doi:

$609 \quad 10.1063 / 1.1728579$

610 Hata, M., Matsushima, N., Takakura, S., Utsugi, M., Hashimoto, T., Uyeshima, M.,

611 (2018), Three-dimensional electrical resistivity modeling to elucidate the crustal magma

612 supply system beneath Aso caldera, Japan. J. Geophys. Res. Solid Earth, 123, 6334-6346,

613 doi: 10.1029/2018JB015951

614 Heap, M.J., Farquharson, J.I., Wadsworth, F.B., Kolzenburg, S., Russell, J.K., (2015),

615 Timescales for permeability reduction and strength recovery in densifying magma, Earth

616 Planet. Sci. Lett., 429, 223-233, doi: 10.1016/j.eps1.2015.07.053

617 Heap, M. J., et al., (2014), Microstructural controls on the physical and mechanical

618 properties of edifice-forming andesites at Volcán de Colima, Mexico, J. Geophys. Res. 
619 Solid Earth, 119, 2925-2963, doi:10.1002/2013JB010521

620 Heise, W., et al., (2016), Imaging the deep source of the Rotorua and Waimangu

621 geothermal fields, Taupo Volcanic Zone, New Zealand, J. Volcanol. Geotherm. Res., 314,

622 39-48, doi: 10.1016/j.jvolgeores.2015.10.017

623 Heise, W., Caldwell, T. G., Bibby, H. M., Bennie, S. L., (2010), Three-dimensional

624 electrical resistivity image of magma beneath an active continental rift, Taupo Volcanic

625 Zone, New Zealand, Geophys. Res. Lett., 37, L10301, doi:10.1029/2010GL043110

626 Heise, W., Caldwell, T. G., Bibby, H. M., Bannister, S. C., (2008), Three-dimensional

627 modelling of magnetotelluric data from the Rotokawa geothermal field, Taupo Volcanic

628 Zone, New Zealand, Geophy. J. Inter., 173, 740-750, doi: 10.1111/j.1365-

629 246X.2008.03737.x

630 Heise, W., et al., (2007), Melt distribution beneath a young continental rift: The Taupo

631 Volcanic Zone, New Zealand, Geophys. Res. Lett., 34, L14313,

632 doi:10.1029/2007GL029629

633 Heise, W., Caldwell, T. G., Bibby, H.M., Brown, C., (2006), Anisotropy and phase splits

634 in magnetotellurics, Phys. Earth Planet. Interior, 158, 107-121, doi: 
636 Hill, G. J., et al., (2009), Distribution of melt beneath Mount St Helens and Mount Adams

637 inferred from magnetotelluric data, Nature Geosci, 2, 785-789, doi:10.1038/ngeo661

638 Hohmann, G. W., (1975), Three-dimensional induced polarization and electromagnetic

639 modeling, Geophys., 40, 309-324, doi: 10.1190/1.1440527

640 Ichiki, M., et al., (2015), Electrical image of subduction zone beneath northeastern Japan,

641 J. Geophys. Res. Solid Earth, 120, 7937-7965, doi:10.1002/2015JB012028

642 Ikegaya, T., and Yamamoto, M., (2020), Spatio-temporal characteristics and focal

643 mechanisms of deep low-frequency earthquakes beneath Zao volcano, Japan, In:

644 Abstracts of 2020 EGU General Assembly, EGU2020-12533, doi: 10.5194/egusphere-

645 egu2020-12533

646 Japan Meteorological Agency, (2013), Azumayama. In: Japan Meteorological Agency,

647 The Volcanological Society of Japan (ed.) National catalogue of the active volcanoes in 648 Japan, 4th ed. Japan Meteorological Agency, Tokyo, 649 https://www.data.jma.go.jp/svd/vois/data/tokyo/STOCK/souran_eng/volcanoes/034_azu 650 mayama.pdf 
651 Kariya, K. A., and Shankland, T. J., (1983), Electrical conductivity of dry lower crustal

652 rocks. Geophys., 48 (1), 52-61, doi:10.1190/1.1441407

653 Kimura, J., and Yoshida, T., (2006), Contributions of Slab Fluid, Mantle Wedge and Crust

654 to the Origin of Quaternary Lavas in the NE Japan Arc, J. Petrol., 47, 2185-2232,

655 doi:10.1093/petrology/eg1041

656 Komori, S., Kagiyama, T., Utsugi, M., Inoue, H., Azuhata, I., (2013), Two-dimensional

657 resistivity structure of Unzen Volcano revealed by AMT and MT surveys, Earth Planets

658 Space, 65, 759-766, doi: 10.5047/eps.2012.10.005

659 Koyama, J., (2015), Is it true that great earthquakes induce large volcanic eruptions

660 worldwide?, Geophys. Bull. Hokkaido Univ., 78, 53-68, doi: 10.14943/gbhu.78.53

661 Kushnir, A. R. L., et al., (2016), Probing permeability and microstructure: Unravelling

662 the role of a low-permeability dome on the explosivity of Merapi (Indonesia), J. Volcanol.

663 Geotherm. Res., 316, 56-71, doi: 10.1016/j.jvolgeores.2016.02.012

664 Laumonier, M., Gaillard, F., Muir, D., Blundy, J., Unsworth, M., (2017), Giant magmatic

665 water reservoirs at mid-crustal depth inferred from electrical conductivity and the growth

666 of the continental crust, Earth Planet. Sci. Lett., 457, 173-180, doi: 
668 Laumonier, M., Gaillard, F., Sifre, D., (2015), The effect of pressure and water

669 concentration on the electrical conductivity of dacitic melts: implication for 670 magnetotelluric imaging in subduction areas, Chem. Geol., 418, doi:

$671 \quad$ 10.1016/j.chemgeo.2014.09.019

672 Marshall, W. L., and Frantz, J. D., (1987), Electrical conductance measurements of dilute,

673 aqueous electrolytes at temperatures to $800^{\circ} \mathrm{C}$ and pressures to 4000 bars: Techniques and

674 interpretations, In: Barnes, H. L., Ulmer, G. C. (Eds.), Hydrothermal Experimental

675 Techniques, Wiley-Interscience, Chap. 11, 261-292

676 Matsunaga, Y., et al., (2020), Magmatic hydrothermal system inferred from the resistivity

677 structure of Kusatsu-Shirane Volcano, J. Volcanol. Geotherm. Res., 390, 106742, doi:

$678 \quad$ 10.1016/j.jvolgeores.2019.106742

679 McGary, R. S., Evans, R. L., Wannamaker, P. E., Elsenbeck, J., Rondenay, S., (2014),

680 Pathway from subducting slab to surface for melt and fluids beneath Mount Rainier,

681 Nature, 511, 338-341, doi:10.1038/nature13493

682 Michaut, C., Bercovici, D., Sparks, R. S. J., (2009), Ascent and compaction of gas rich 
683 magma and the effects of hysteretic permeability, Earth Planet. Sci. Lett., 282(1-4), 258-

684 267, doi: 10.1016/j.eps1.2009.03.026

685 Mueller, S., Melnik, O., Spieler, O., Scheu, B., Dingwell, D. B., (2005), Permeability and

686 degassing of dome lavas undergoing rapid decompression: An experimental

687 determination, Bull. Volcanol., 67 (6), 526-538, doi: 10.1007/s00445-004-0392-4

688 Nesbitt, B. E., (1993), Electrical resistivities of crustal fluids, J. Geophys. Res., 98 (B3),

689 4301-4310, doi: 10.1029/92JB02576

690 Nishimura, T., (2017), Triggering of volcanic eruptions by large earthquakes, Geophys.

691 Res. Lett., 44, 7750-7756, doi: 10.1002/2017GL074579

692 Okumura, S., and Sasaki, O., (2014), Permeability reduction of fractured rhyolite in

693 volcanic conduits and its control on eruption cyclicity, Geology, 42, 843-846, doi:

$694 \quad 10.1130 / \mathrm{G} 35855.1$

695 Peacock, J. R., Thiel, S., Reid, P., Heinson, G., (2012), Magnetotelluric monitoring of a

696 fluid injection: Example from an enhanced geothermal system, Geophys. Res. Lett., 39,

697 L18403, doi: 10.1029/2012GL053080

698 Rust, A. C., and Cashman, K. V., (2011), Permeability controls on expansion and size 
699 distributions of pyroclasts, J. Geophys. Res. Solid Earth, 116, B11202,

700 doi:10.1029/2011JB008494.

701 Rust, A. C., and Cashman, K. V., (2004), Permeability of vesicular silicic magma: inertial 702 and hysteresis effects, Earth Planet. Sci. Lett., 228, 93-107, doi:

$703 \quad 10.1016 /$ j.epsl.2004.09.025

704 Seki, S., et al., (2020), Volcanic Activity in 2018-19 at Azumayama Volcano, Japan, Quart.

705 J. Seismology (revised)

706 Siripunvaraporn, W., and Egbert, G. D., (2009), WSINV3DMT: Vertical magnetic field

707 transfer function inversion and parallel implementation, Phys. Earth Planet. Int., 173,

708 317-329, doi: 10.1016/j.pepi.2009.01.013

709 Siripunvaraporn, W., Egbert, G. D., Lenbury, Y., Uyeshima, M., (2005), Three-

710 dimensional magnetotelluric inversion: data-space method, Phys. Earth Planet. Inter., 150,

711 3-14, doi: 10.1016/j.pepi.2004.08.023

712 Sisson, T. W., and Bacon, C. R., (1999), Gas-driven filter pressing in magmas, Geology,

71327 (7), 613-616, doi: 10.1130/0091-7613(1999)027<0613:GDFPIM>2.3.CO;2

714 Takada, Y., and Fukushima, Y., (2013), Volcanic subsidence triggered by the 2011 Tohoku 
715 earthquake in Japan, Nature Geosci, 6, 637-641, doi:10.1038/ngeo1857

716 Takahashi, T., et al., (2013), Primary Magmas at the Volcanic Front of the NE Japan Arc:

717 Coeval Eruption of Crustal Low-K Tholeiitic and Mantle-derived Medium-K Calc-

718 Alkaline Basalts at Azuma Volcano, J. Petrol., 54 (1), 103-148, doi:

719 10.1093/petrology/egs065

720 Tanaka, A., Yamano, M., Yano, Y., Sasada, M., (2004), Geothermal gradient and heat flow

721 data in and around Japan (I): Appraisal of heat flow from geothermal gradient data, Earth

722 Planet Space, 56, 1191-1194, doi: 10.1186/BF03353339

723 Tatsumi, Y., et al., (2008), New Insights into Andesite Genesis: the Role of Mantle-

724 derived Calc-alkalic and Crust-derived Tholeiitic Melts in Magma Differentiation

725 beneath Zao Volcano, NE Japan, J. Petrol., 49, 1971-2008, doi: 10.1093/petrology/egn055

726 Toya, N., Ban, M., Shinjo, R., (2005), Petrology of Aoso volcano, northeast Japan arc:

727 temporal variation of the magma feeding system and nature of low-K amphibole andesite

728 in the Aoso-Osore volcanic zone, Contrib Mineral Petrol, 148, 566-581, doi:

$729 \quad 10.1007 / \mathrm{s} 00410-004-0621-\mathrm{Z}$

730 Tsukamoto, K., et al., (2018), Three-dimensional resistivity structure of Iwo-yama 
731 volcano, Kirishima Volcanic Complex, Japan: relationship to shallow seismicity, surface

732 uplift, and a small phreatic eruption. Geophys. Res. Lett. 45, 12821-12828, doi:

$733 \quad 10.1029 / 2018 G L 080202$

734 Wallace, P. J., (2005), Volatiles in subduction zone magmas: concentrations and fluxes

735 based on melt inclusion and volcanic gas data, J. Volcanol. Geotherm. Res., 140, $217-$

$736 \quad 240$, doi: 10.1016/j.jvolgeores.2004.07.023

737 Wannamaker, P. E., Hohmann, G. W., Ward, S. H., (1984), Magnetotelluric responses of

738 three-dimensional bodies in layered earths, Geophys., 49, 1517-1533, doi:

$739 \quad 10.1190 / 1.1441777$

740 Wright, H. M.N., Cashman, K. V., Gottesfeld, E. H., Roberts, J. J., (2009), Pore structure

741 of volcanic clasts: Measurements of permeability and electrical conductivity, Earth Planet.

742 Sci. Lett., 280, 93-104, doi: 10.1016/j.eps1.2009.01.023

743 Yamamoto, M., (2014), Volcanic activities of Hakkoda volcano after the 2011 Tohoku-

744 Oki earthquake, In: Abstracts of 2014 Japan Geoscience Union Meetings, SVC55-P06e,

745 Yokohama, Japan, 28 April to 2 May 2014

746 Yamamoto, T., (2005), Eruptive history of Azuma volcano, NE Japan during last 7000 
747 years: Stratigraphy and magma-plumbing system of the Azuma-Jododaira products, J.

748 Geol. Soc. Japan, 111 (2), 94-110, doi: 10.5575/geosoc.111.94 (in Japanese with English

749 abstract and figure caption)

750 Yoshida T., et al., (2014), Evolution of late Cenozoic magmatism and the crust-mantle

751 structure in the NE Japan Arc, IN: Gomez-Tuena, A., Straub, S. M., Zellmer, G. F. (eds)

752 Orogenic Andesites and Crustal Growth, Geological Society, London, Special

753 Publications, 385, 335-387, doi: 10.1144/SP385.15

754 Yoshida, Y., et al., (2012), Crustal Deformation Observed by GPS around Azuma Volcano,

755 Quart. J. Seismology, 76, 1-8 (in Japanese with English abstract and figure caption)

756 Yoshigai, Y., et al., (2019), Recent volcanic activity in Azumayama, Japan, In Abstracts

757 of AGU Fall Meeting, V51J-0227, San Francisco, CA, USA, 9-13 December 2019

758 Yoshimura, R., et al., (2018), Resistivity characterisation of Hakone volcano, Central

759 Japan, by three-dimensional magnetotelluric inversion. Earth Planets Space, 70, 66, doi:

$760 \quad 10.1186 / \mathrm{s} 40623-018-0848-\mathrm{y}$

761 Zhdanov, M. S., Lee, S. K., Yoshioka, K., (2006), Integral equation method for 3D

762 modeling of electromagnetic fields in complex structures with inhomogeneous 
763 background conductivity, Geophys., 71, G333-G345, doi: 10.1190/1.2358403

764 


\section{Figure Captions}

766 Figure 1. Study area and the MT and GDS observation sites. (a) Location of study area.

767 (b) Regional map of study area and adjacent locations. (c) Local view of the study area 768 with the 18 MT and GDS observation sites represented by the white circles. The red 769 triangle shows the location of the active fumarole in Oana crater; black triangles designate 770 Azumayama Volcano edifices: 1. Mt. Issaikyo, 2. Azuma-kofuji, 3. Higashi-azuma, 4.

771 Naka-azuma, 5. Nishi-azuma. Contour intervals on the surface topography are labeled in 772 meters above sea level.

773 Figure 2. The $\tan ^{-1}\left(\Phi_{2}\right)$ of each site at various frequencies or periods (colored circles).

774 White contour lines represent 2.5 width. The black and red triangles are the same as in 775 Figure 1.

776 Figure 3. RMS misfit change in terms of prior model update. Each line and character 777 show RMS misfit change depending on initial prior model (see text). Initial prior model 778 is represented by uniform subsurface resistivity.

779 Figure 4. Plan or map view of the final resistivity model at 0.05, 3.50, 5.50, 7.50, 9.50,

$78012.50 \mathrm{~km}$ depth. Background color represents the logarithmic resistivity value. Black

781 circles, white lines, red character, and black triangles, are observation sites, topographic 
contours, Oana crater, and edifice summits, respectively (cf. Figure 1).

783 Figure 5. Vertical profiles of the final resistivity model in E-W direction. Top left figure

784 shows the location of each vertical profile. Background colors are the same as in Figure

785 4. The white lines are logarithmic resistivity contours. The origin of the E-W coordinate

786 is fixed at Oana crater.

787 Figure 6. Vertical profile of the final resistivity model in N-S direction. The origin of the

$788 \mathrm{~N}-\mathrm{S}$ coordinate is fixed at Oana crater. Other features are the same as those in Figures 4

789 and 5.

790 Figure 7. Observed (left column), calculated (center column), and misfit (right column)

791 phase tensor ellipse of each site at various periods or frequency. Observed and calculated

792 phase tensor ellipse magnitudes are normalized by observed maximum principal axis

793 magnitude at each site and period/frequency, and are filled with colors corresponding to

$794 \tan ^{-1}\left(\Phi_{2}\right)$ designated by the color scale. The misfit phase tensor uses the definition of

795 Peacock et al. (2012), and these are filled with colors corresponding to $\Delta \Phi_{\text {principal }}$

796 (Equation 18) designated by the color scale. Azimuth of the white bars represents

$797 \alpha_{o b s}+\beta_{o b s}+\pi / 2$ direction (length is arbitrary). 
798 Figure 8. Plan view of CRT input and output models using checkerboxes about $3 \mathrm{~km}$ to

799 a side. The checkerboxes in the input model are embedded at 6 to $9 \mathrm{~km}$ depth, and those

800 in the output models are shown at $7.5 \mathrm{~km}$ depth (cf. Figure 10). Input checkerbox

801 resistivity (red) is $1 \Omega \mathrm{m}$ and other blocks are $1000 \Omega \mathrm{m}$ except ocean $(0.3333 \Omega \mathrm{m})$ and air

802 blocks $\left(10^{12} \Omega \mathrm{m}\right)$. Output models are shown at the same iteration times of the final model

803 (Figure 4) at each updated prior model. Solid lines show the calculation mesh. White

804 contour represents surface topography. NS, EW coordinates are set using Oana crater's

805 location as origin.

806 Figure 9. Same with Figure 8 , but using checkerboxes about $5 \mathrm{~km}$ to a side. The

807 checkerboxes are embedded at 5 to $10 \mathrm{~km}$ depth, and the output models are shown at 7.5

808 km depth (cf. Figure 10).

809 Figure 10. Vertical profile in E-W direction of CRT input and output models. Left and

810 right columns represent the models using checkerboxes with one side 3 and $5 \mathrm{~km}$,

811 respectively.

812 Figure 11. Perspective view of isosurface of (a) 3 and (b) $1 \Omega \mathrm{m}$ in 3 to $15 \mathrm{~km}$. Bottom of

813 each figure shows observation site (solid circle) edifice (solid triangle) surface 
814 topography (black contour line), and the vertical projection of the isosurface (shade).

815 Figure 12. F-statistic change of each site in terms of resistivity change of target area

816 shown in Figure 11. (a) F-statistic change obtained by changing resistivity inside

817 isosurface in Figure 11a. (b) Same with (a), but obtained by changing resistivity inside

818 Figure 11b. Confidence level of 95, 90, and $67 \%$ are shown in blue, red, and green lines,

819 respectively. The $67 \%$ and $90 \%$ CIR in (a) are determined to be 0.3 to $5 \Omega \mathrm{m}$ (dark shade)

820 and 0.02 to $70 \Omega \mathrm{m}$ (light shade), respectively. The $95 \% \mathrm{CIR}$ in (a) and 67 to $95 \% \mathrm{CIR}$

821 in (b) are not available.

822 Figure 13. Mogi source locations of the two (solid circle) or three (solid star) inflation

823 source models by Seki et al. (2020) superimposed on the N-S vertical profile of the final

824 resistivity model $\left(H^{\prime}-H\right.$ profile in Figure 6$)$.

825 Figure 14. Bulk resistivity (solid line) of dacitic melt and rock complex at $900{ }^{\circ} \mathrm{C}, 0.15$

$826 \mathrm{GPa}$ as a function of melt fraction and of water content in the dacitic melt. Gray shaded

827 area represents the $67 \%$ CIR of Figure 11a, and the solid lines show water content of

828 dacitic melt in weight percent. Note that the upper and lower bound of $67 \%$ CIR is bottom

829 and top of the gray shaded area, respectively. Melt resistivity is calculated from 
830 Laumonier et al. (2015). Solid phase resistivity is fixed at $1000 \Omega \mathrm{m}$ (e.g. granite data of

831 Kariya \& Shankland, 1983).

832 Figure 15. Bulk reistivity (solid line) of andesitic melt and rock complex at $900{ }^{\circ} \mathrm{C}, 0.29$

$833 \mathrm{GPa}$ as a function of melt fraction and of water content in the andesitic melt. Melt

834 resistivity calculations from Guo et al. (2017) are shown by the broken line, and from

835 Laumonier et al. (2017) are shown by the solid line. Solid phase resistivity is fixed at 500

$836 \Omega \mathrm{m}$ (e.g. rhyolite data of Kariya \& Shankland, 1983). Others are the same as Figure 14.

837 Figure 16. Bulk resistivity of two phases (hydrothermal fluid-rock) as a function of the

838 hydrothermal fluid fraction (solid line). Hydrothermal fluid resistivity is assumed to be

8390.1 or $0.3 \Omega \mathrm{m}$. Rock resistivity is fixed at $1000 \Omega \mathrm{m}$ (cf. Figure 14). Green, orange, and

840 pink columns show percolation threshold porosity in effusive and explosive eruptions,

841 and change point of permeability-porosity relationship, respectively. Red and green lines

842 show the upper bounds of $67 \%$ and $90 \%$ CIR of the conductor (cf. Figure 11a). Oblique

843 pattern represents likely resistivity range at the Mogi inflation source location, assuming

844 that the upper bound of CIR of the conductor restricts the lower bound of resistivity at

845 the Mogi inflation source. 


\section{Figures}
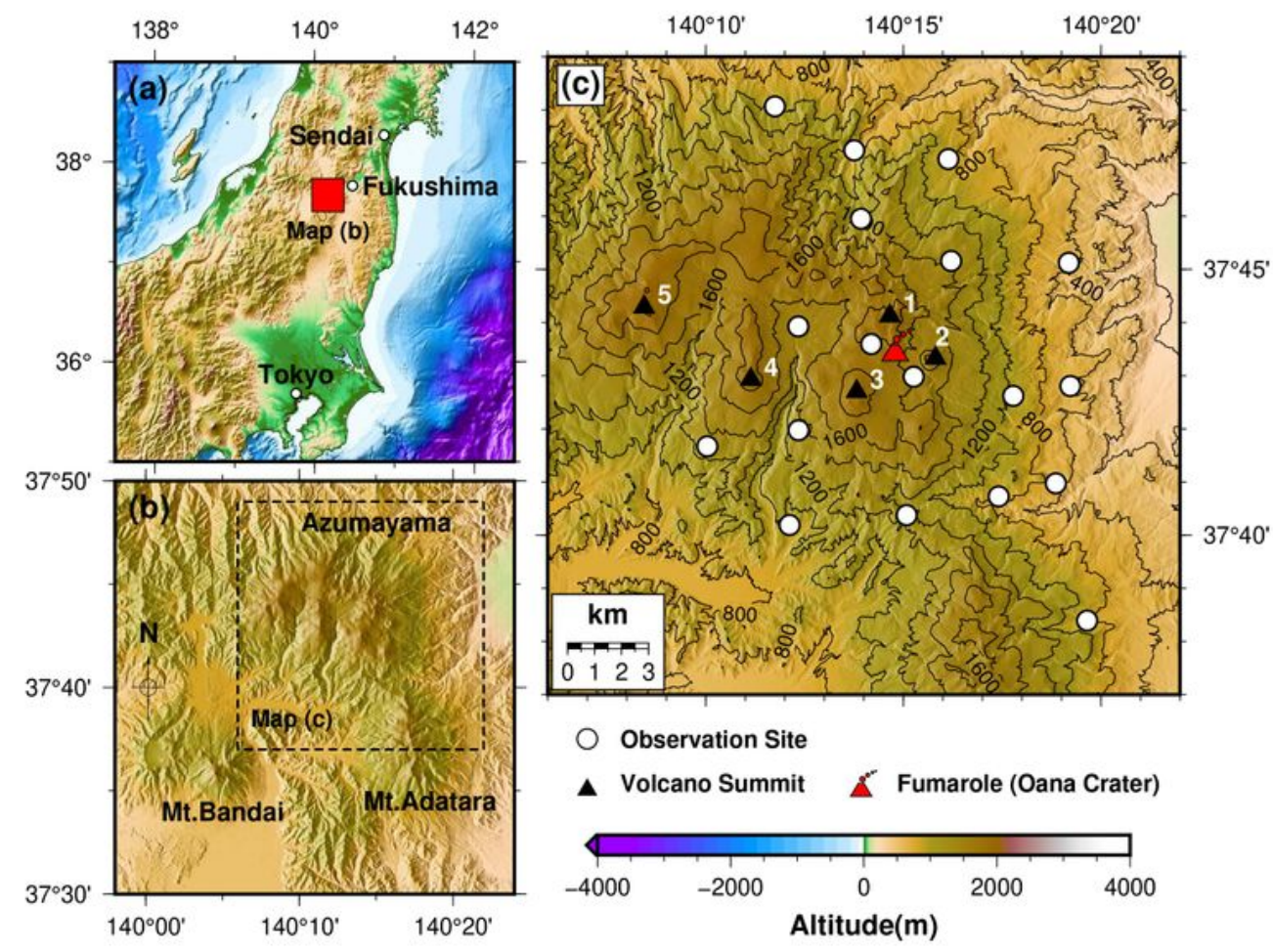

\section{Figure 1}

Study area and the MT and GDS observation sites. (a) Location of study area. (b) Regional map of study area and adjacent locations. (c) Local view of the study area with the 18 MT and GDS observation sites represented by the white circles. The red triangle shows the location of the active fumarole in Oana crater; 
black triangles designate Azumayama Volcano edifices: 1. Mt. Issaikyo, 2. Azuma-kofuji, 3. Higashiazuma, 4. Naka-azuma, 5. Nishi-azuma. Contour intervals on the surface topography are labeled in meters above sea level. Note: The designations employed and the presentation of the material on this map do not imply the expression of any opinion whatsoever on the part of Research Square concerning the legal status of any country, territory, city or area or of its authorities, or concerning the delimitation of its frontiers or boundaries. This map has been provided by the authors.
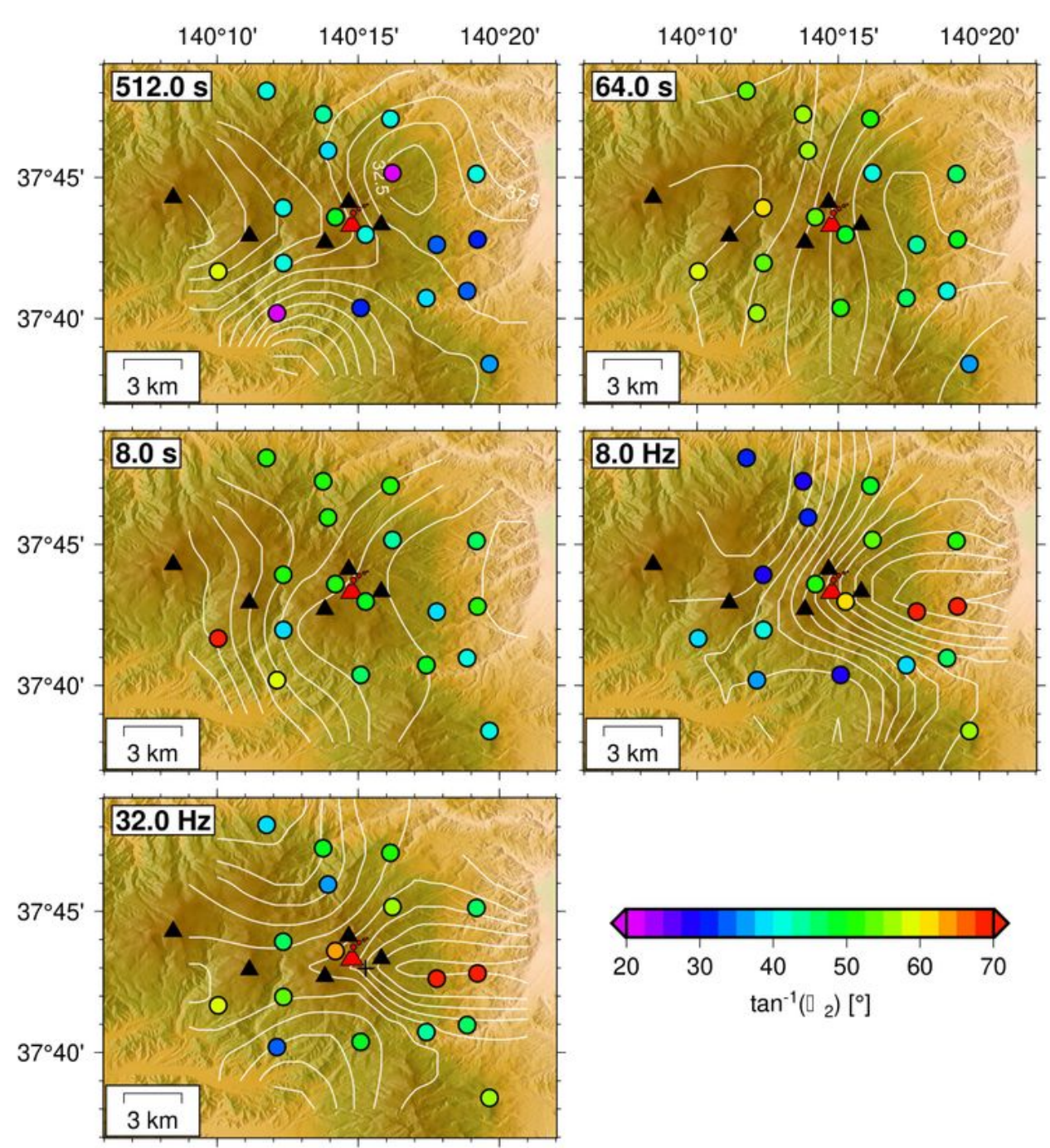

Figure 2 
The tan-1(\$2) of each site at various frequencies or periods (colored circles). White contour lines represent 2.5 width. The black and red triangles are the same as in Figure 1.

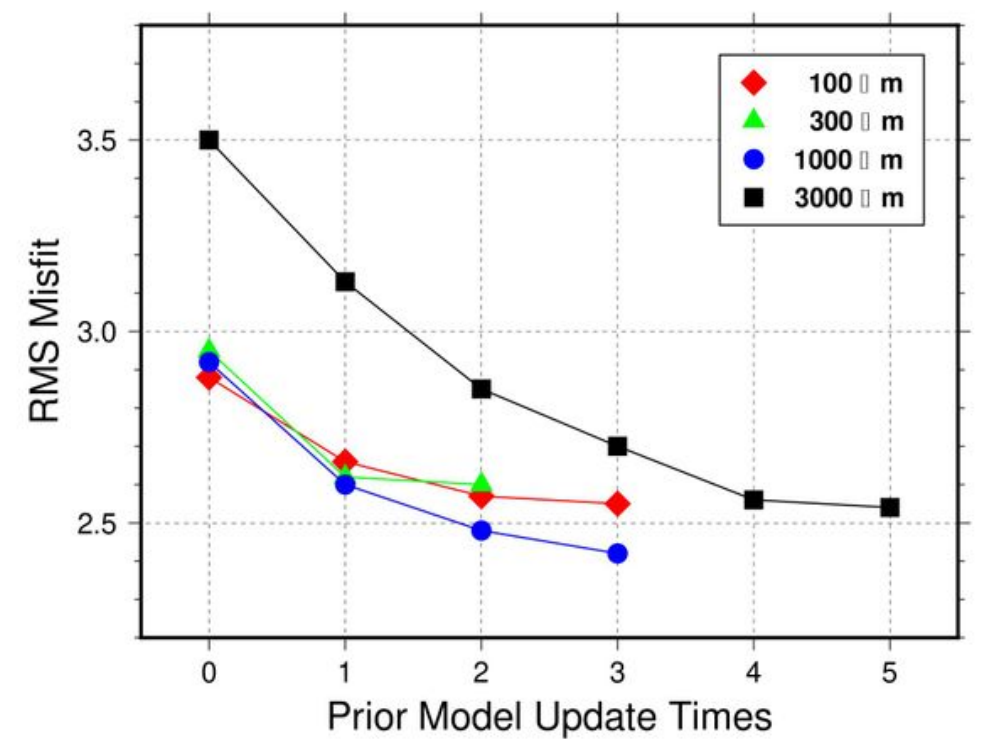

Figure 3

RMS misfit change in terms of prior model update. Each line and character show RMS misfit change depending on initial prior model (see text). Initial prior model is represented by uniform subsurface resistivity. 

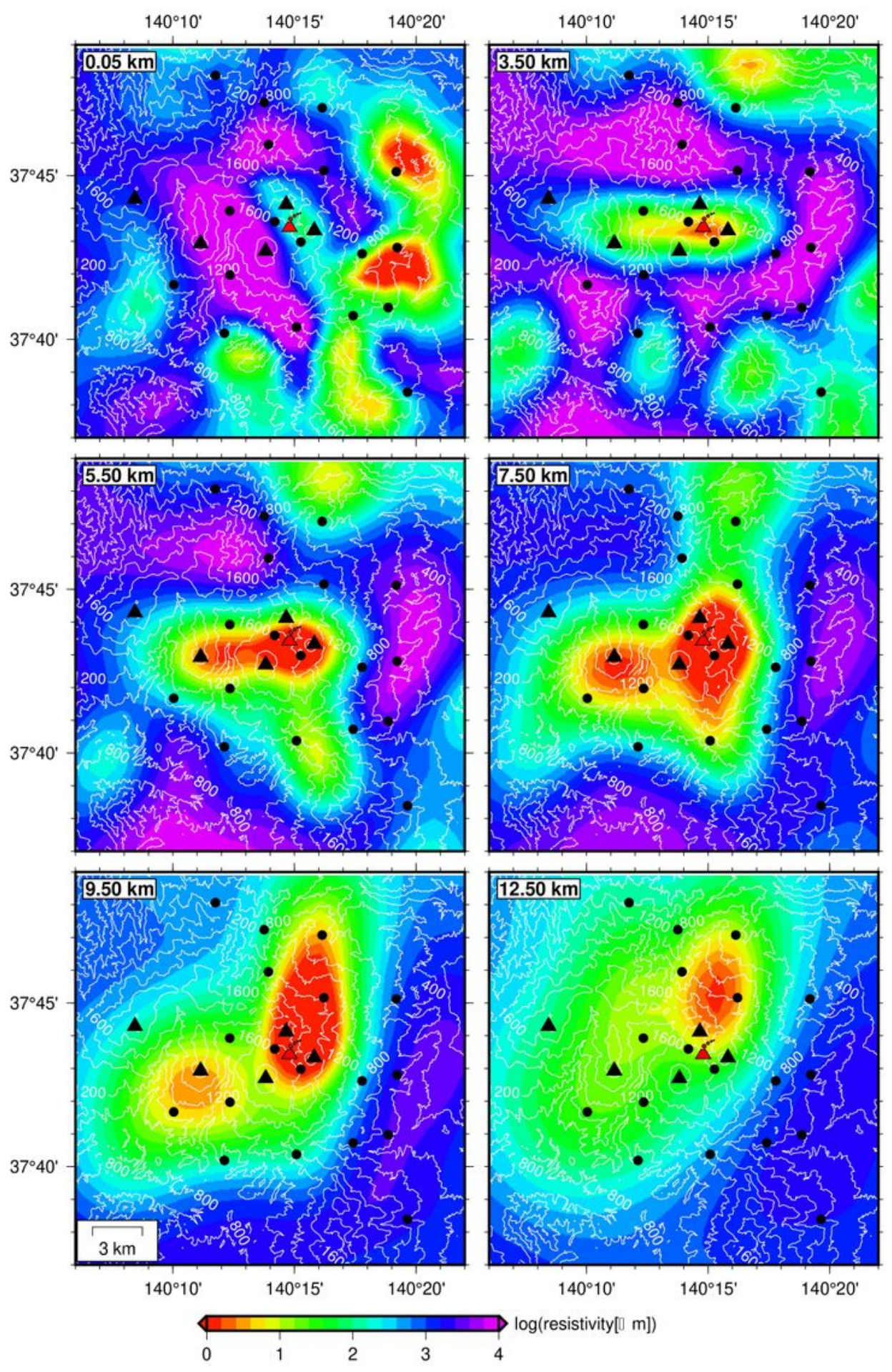

\section{Figure 4}

Plan or map view of the final resistivity model at $0.05,3.50,5.50,7.50,9.50,12.50 \mathrm{~km}$ depth. Background color represents the logarithmic resistivity value. Black circles, white lines, red character, and black triangles, are observation sites, topographic contours, Oana crater, and edifice summits, respectively (cf. Figure 1). 

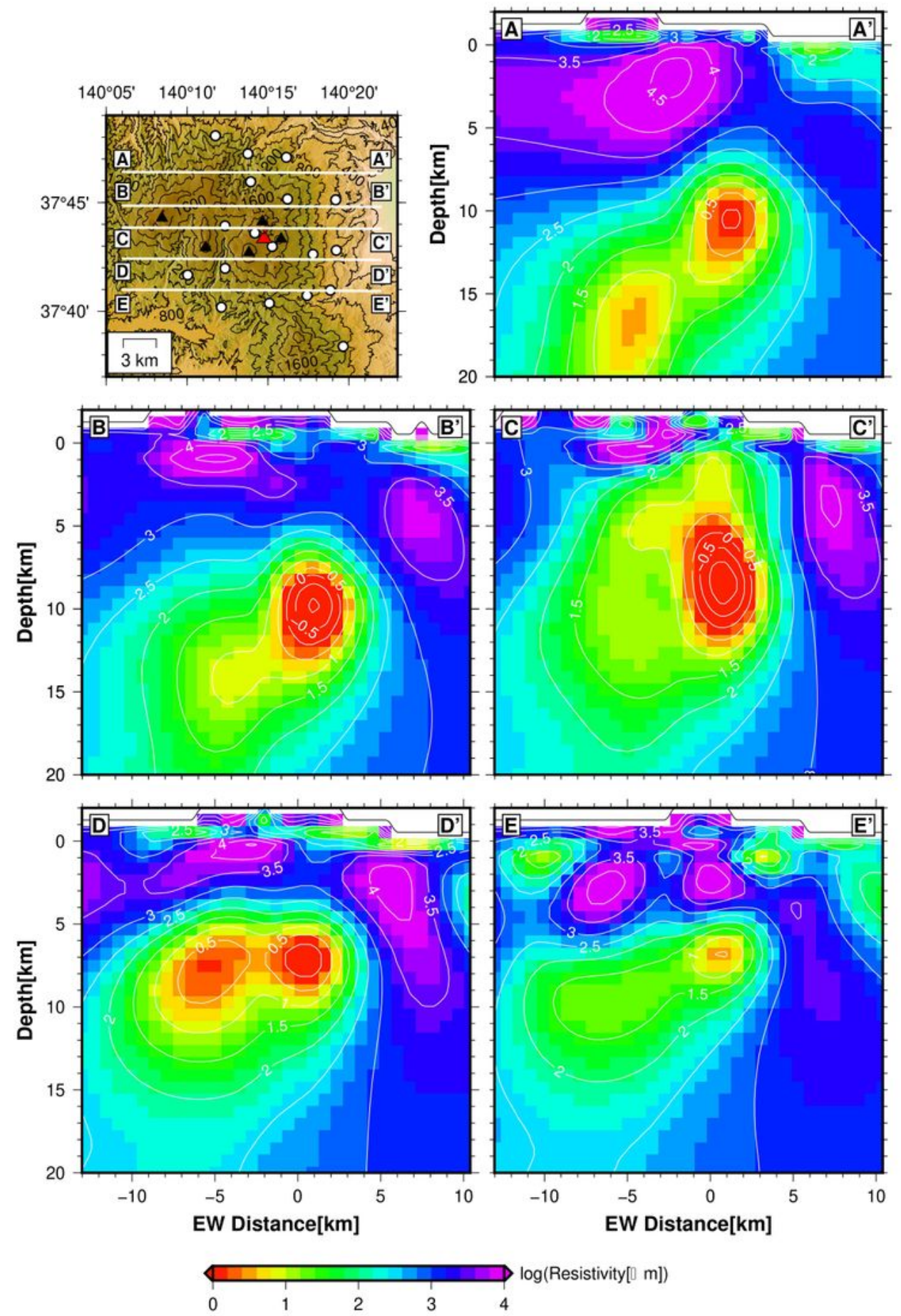

\section{Figure 5}

Vertical profiles of the final resistivity model in E-W direction. Top left figure shows the location of each vertical profile. Background colors are the same as in Figure 4. The white lines are logarithmic resistivity contours. The origin of the E-W coordinate is fixed at Oana crater. 

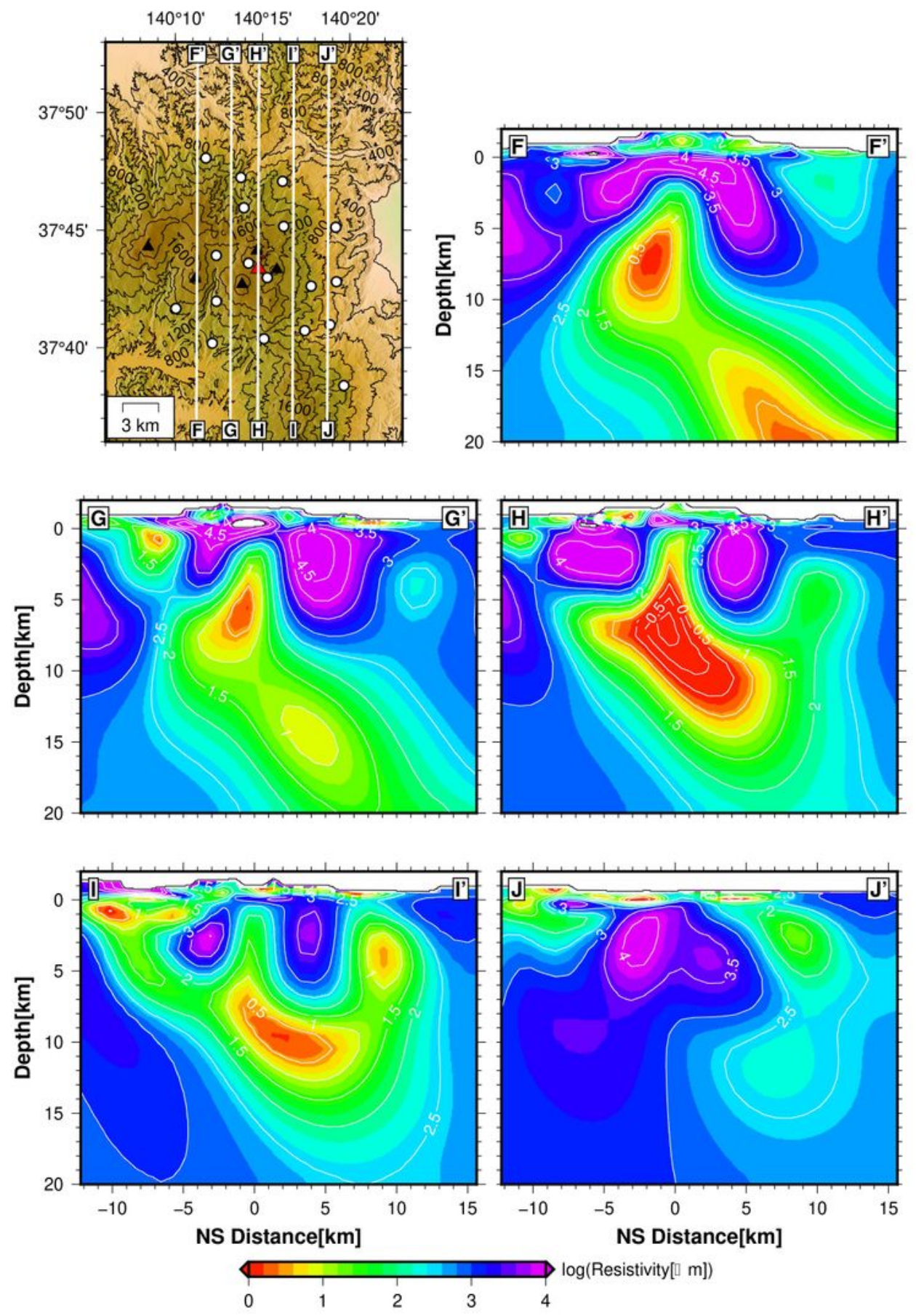

\section{Figure 6}

Vertical profile of the final resistivity model in N-S direction. The origin of the N-S coordinate is fixed at Oana crater. Other features are the same as those in Figures 4 and 5. 


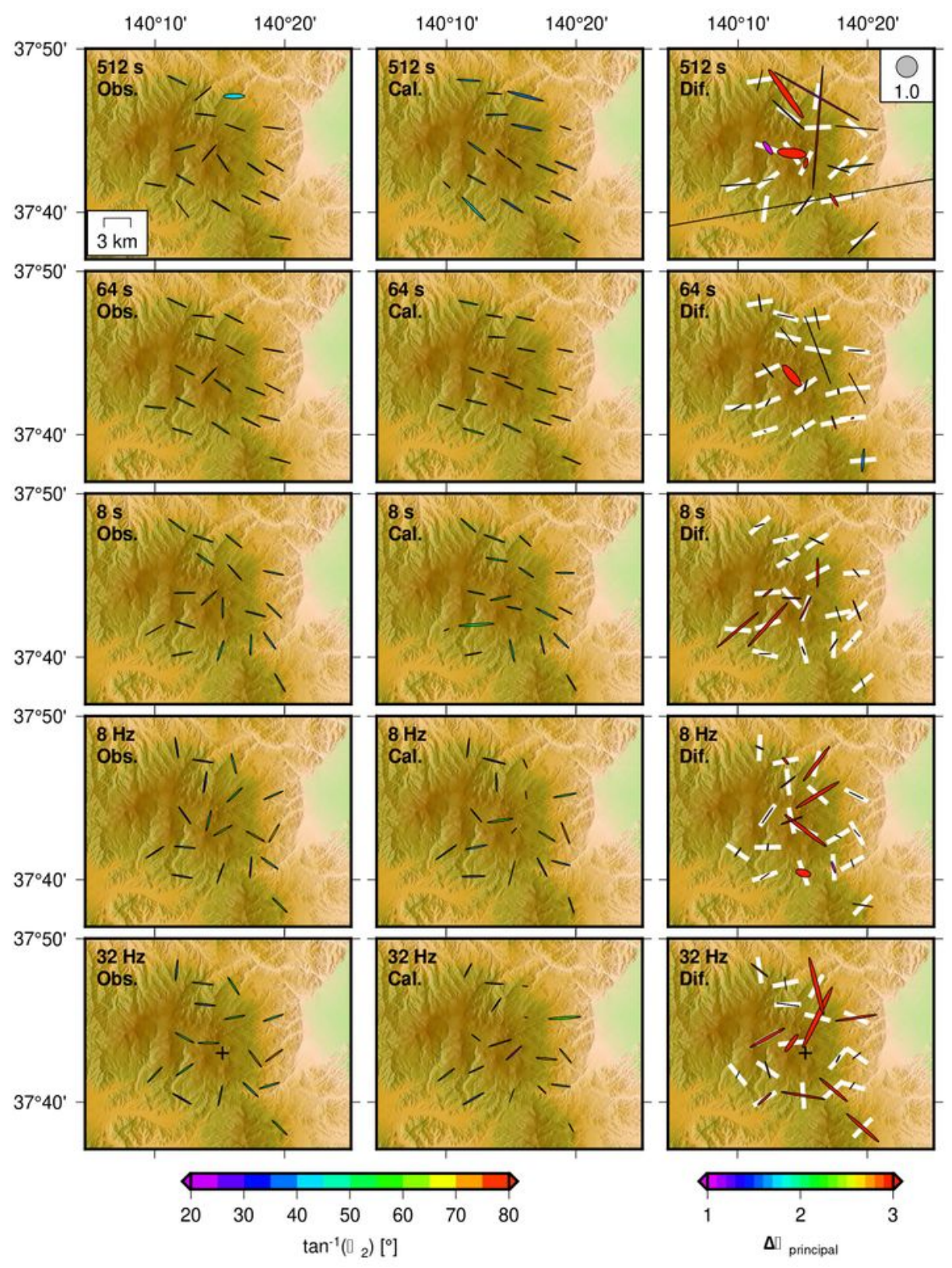

\section{Figure 7}

Observed (left column), calculated (center column), and misfit (right column) phase tensor ellipse of each site at various periods or frequency. Observed and calculated phase tensor ellipse magnitudes are normalized by observed maximum principal axis magnitude at each site and period/frequency, and are filled with colors corresponding to tan-1(Ф2) designated by the color scale. The misfit phase tensor uses the definition of Peacock et al. (2012), and these are filled with colors corresponding to $\Delta$ Фprincipal 
(Equation 18) designated by the color scale. Azimuth of the white bars represents aobs $+\beta o b s+\pi / 2$ direction (length is arbitrary).

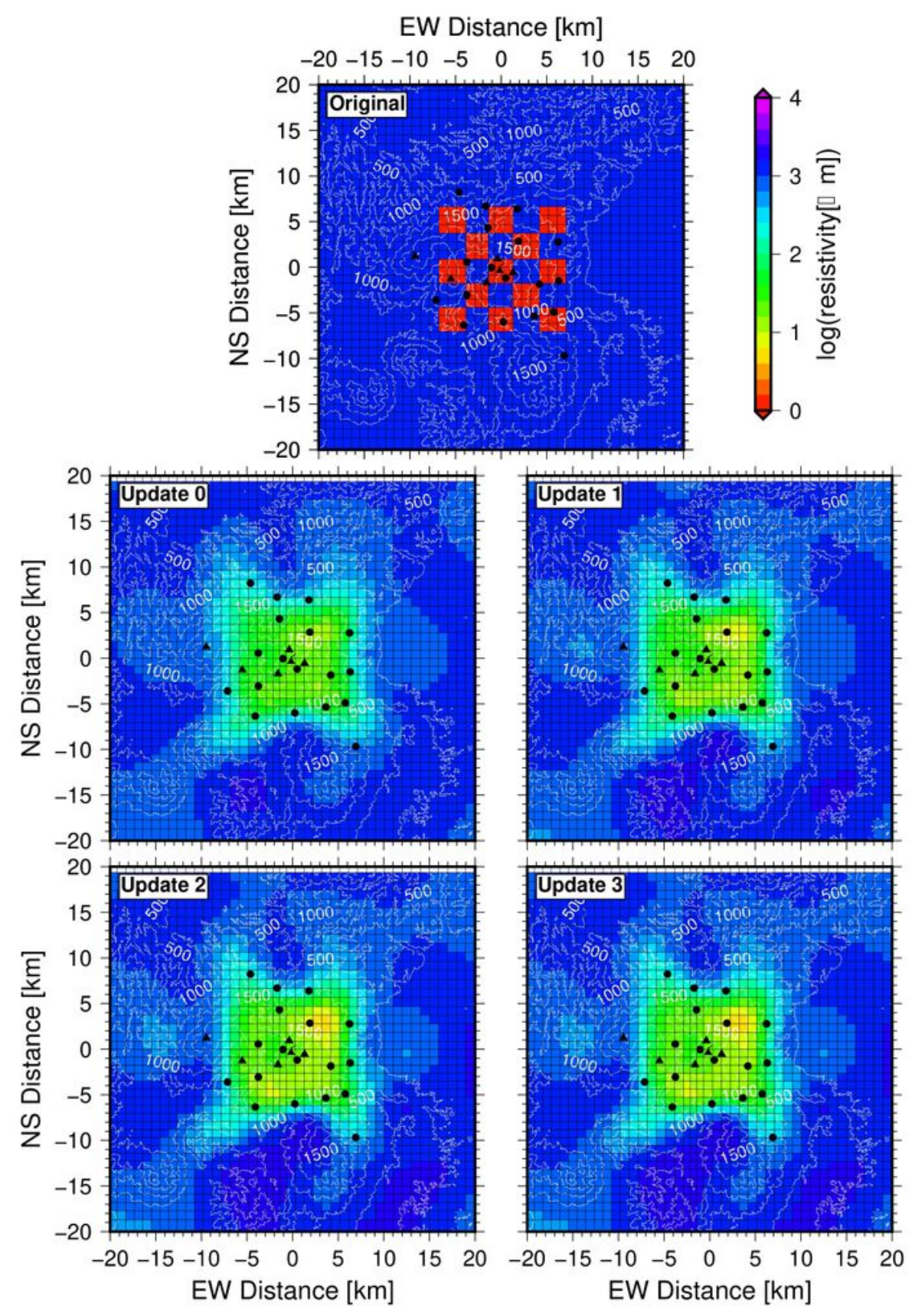

Figure 8

Plan view of CRT input and output models using checkerboxes about $3 \mathrm{~km}$ to a side. The checkerboxes in the input model are embedded at 6 to $9 \mathrm{~km}$ depth, and those in the output models are shown at $7.5 \mathrm{~km}$ depth (cf. Figure 10). Input checkerbox resistivity (red) is $1 \Omega \mathrm{m}$ and other blocks are $1000 \Omega \mathrm{m}$ except 
ocean $(0.3333 \Omega \mathrm{m})$ and air blocks $(1012 \Omega \mathrm{m})$. Output models are shown at the same iteration times of the final model (Figure 4) at each updated prior model. Solid lines show the calculation mesh. White contour represents surface topography. NS, EW coordinates are set using Oana crater's location as origin.

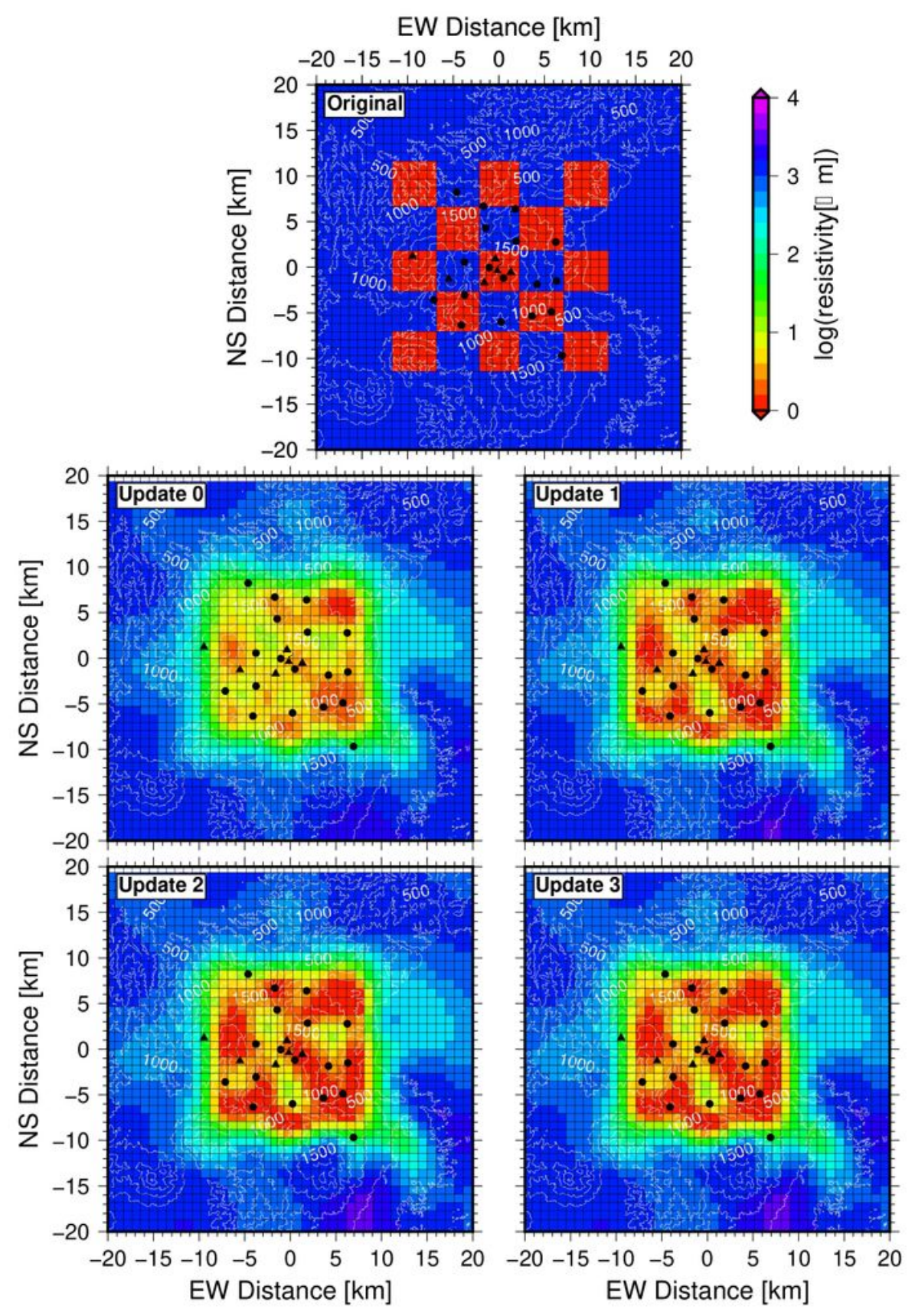

Figure 9

Same with Figure 8, but using checkerboxes about $5 \mathrm{~km}$ to a side. The checkerboxes are embedded at 5 to $10 \mathrm{~km}$ depth, and the output models are shown at $7.5 \mathrm{~km}$ depth (cf. Figure 10). 

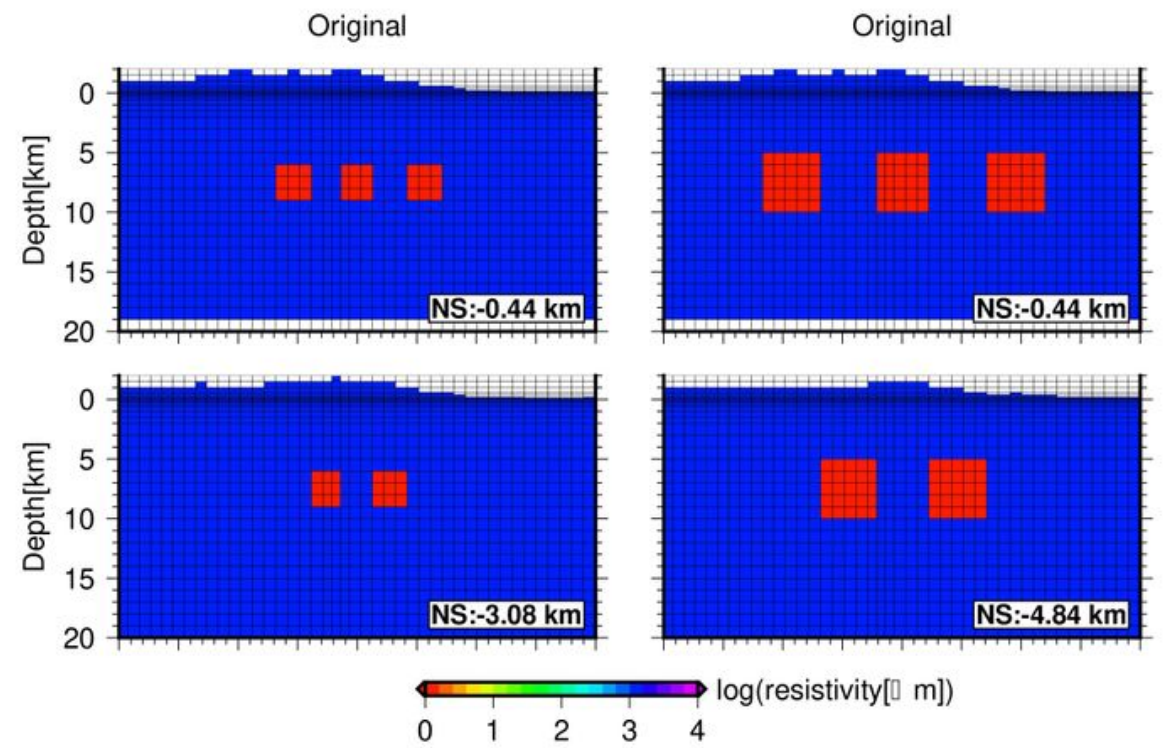

Update 3

$\log$ (resistivity[ $\mathrm{m}]$ )

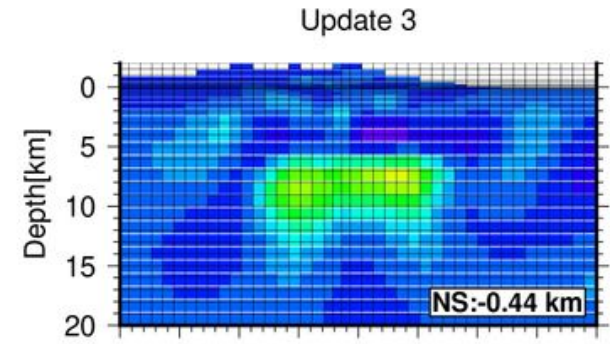

Update 3
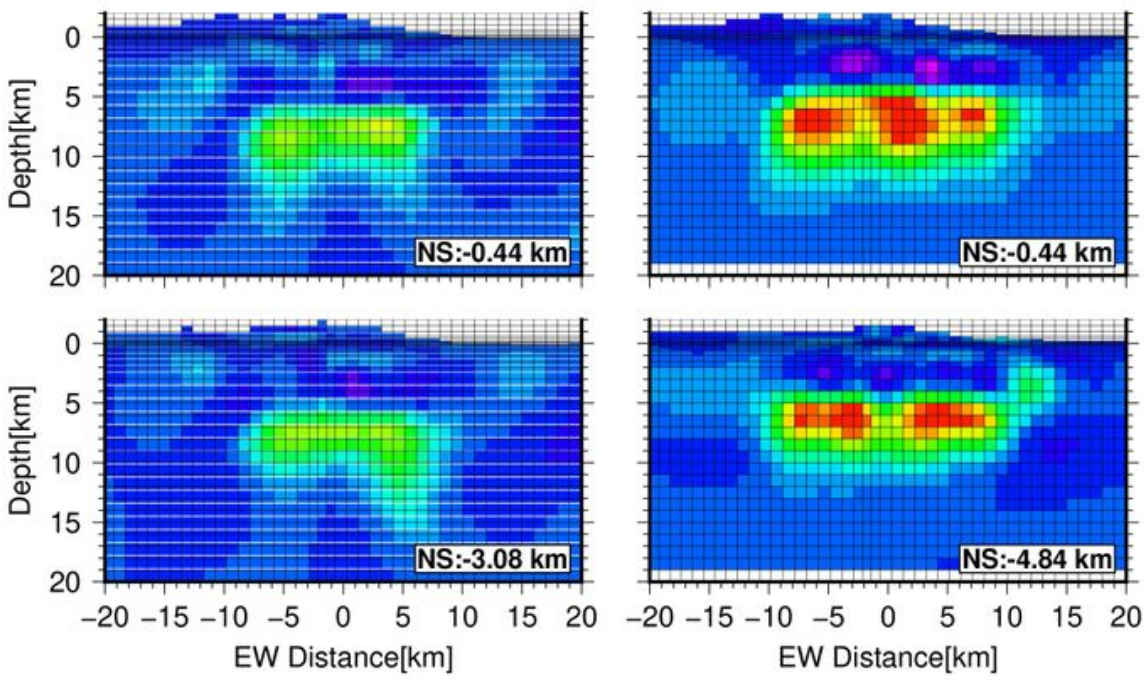

\section{Figure 10}

Vertical profile in E-W direction of CRT input and output models. Left and right columns represent the models using checkerboxes with one side 3 and $5 \mathrm{~km}$, respectively. 

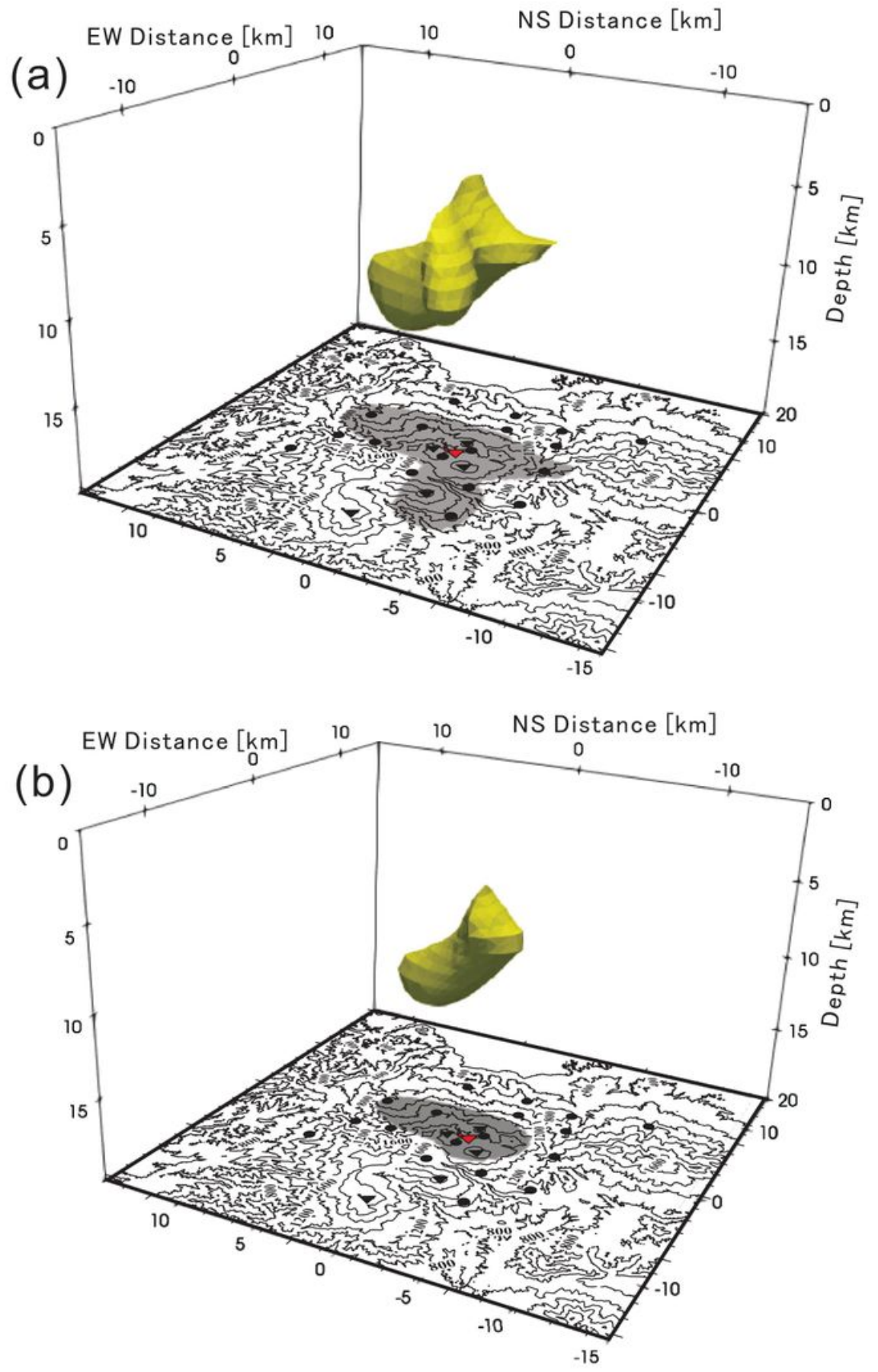

\section{Figure 11}

Perspective view of isosurface of (a) 3 and (b) $1 \Omega \mathrm{m}$ in 3 to $15 \mathrm{~km}$. Bottom of each figure shows observation site (solid circle) edifice (solid triangle) surface topography (black contour line), and the vertical projection of the isosurface (shade). 

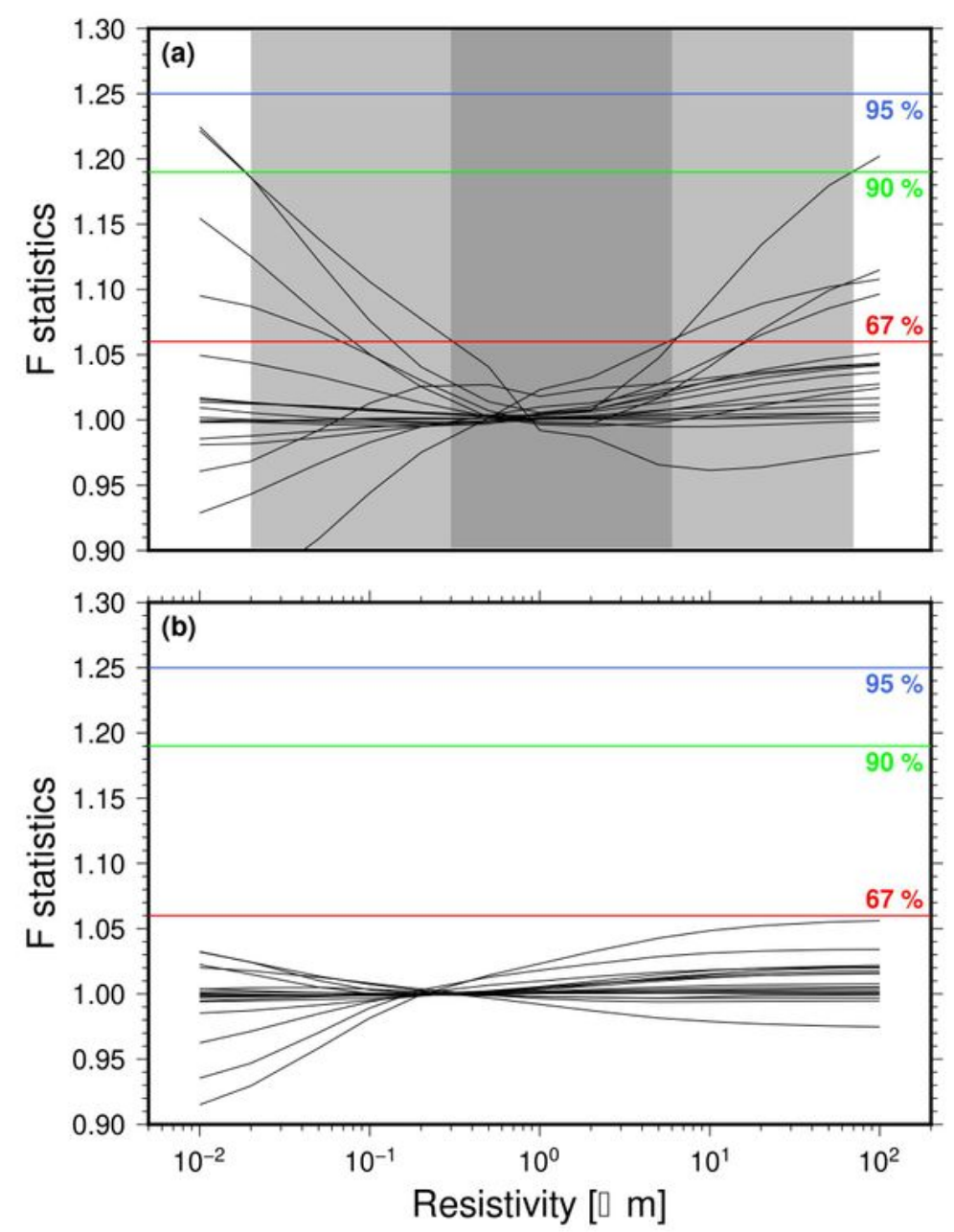

Figure 12

F-statistic change of each site in terms of resistivity change of target area shown in Figure 11. (a) Fstatistic change obtained by changing resistivity inside isosurface in Figure 11a. (b) Same with (a), but obtained by changing resistivity inside Figure $11 \mathrm{~b}$. Confidence level of 95,90 , and $67 \%$ are shown in blue, red, and green lines, respectively. The $67 \%$ and $90 \% \mathrm{CIR}$ in (a) are determined to be 0.3 to $5 \Omega \mathrm{m}$ (dark 
shade) and 0.02 to $70 \Omega \mathrm{m}$ (light shade), respectively. The $95 \% \mathrm{CIR}$ in (a) and 67 to $95 \% \mathrm{CIR}$ in (b) are not available.

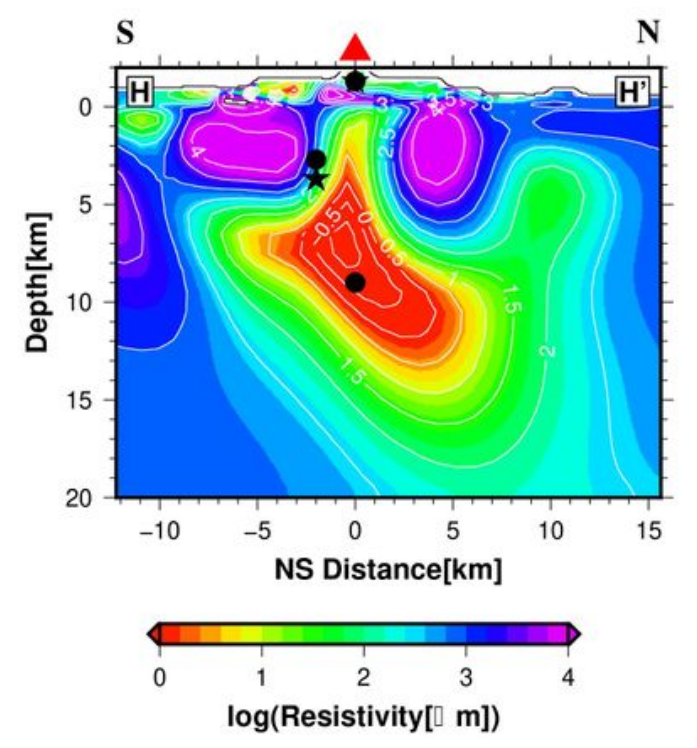

Figure 13

Mogi source locations of the two (solid circle) or three (solid star) inflation source models by Seki et al. (2020) superimposed on the N-S vertical profile of the final resistivity model ( $H^{\prime}-H$ profile in Figure 6). 


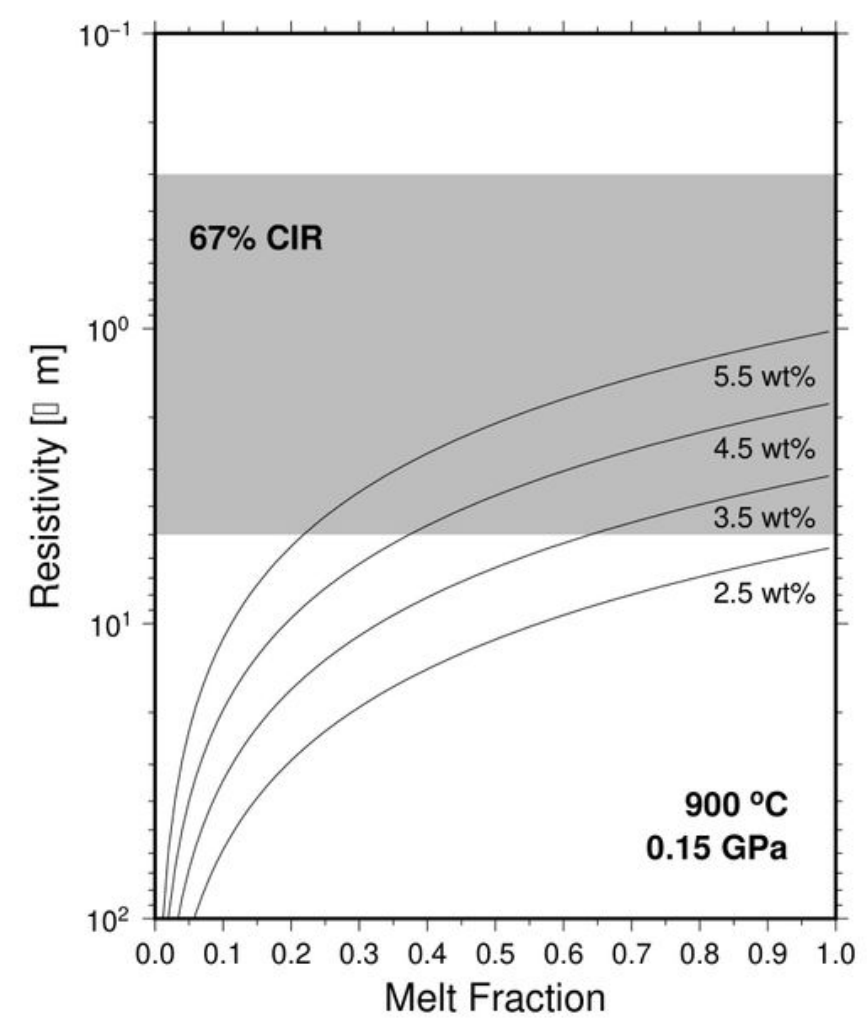

\section{Figure 14}

Bulk resistivity (solid line) of dacitic melt and rock complex at $900 \otimes, 0.15 \mathrm{GPa}$ as a function of melt fraction and of water content in the dacitic melt. Gray shaded area represents the $67 \%$ CIR of Figure 11 , and the solid lines show water content of dacitic melt in weight percent. Note that the upper and lower bound of $67 \% \mathrm{CIR}$ is bottom and top of the gray shaded area, respectively. Melt resistivity is calculated 
from Laumonier et al. (2015). Solid phase resistivity is fixed at $1000 \Omega \mathrm{m}$ (e.g. granite data of Kariya \& Shankland, 1983).

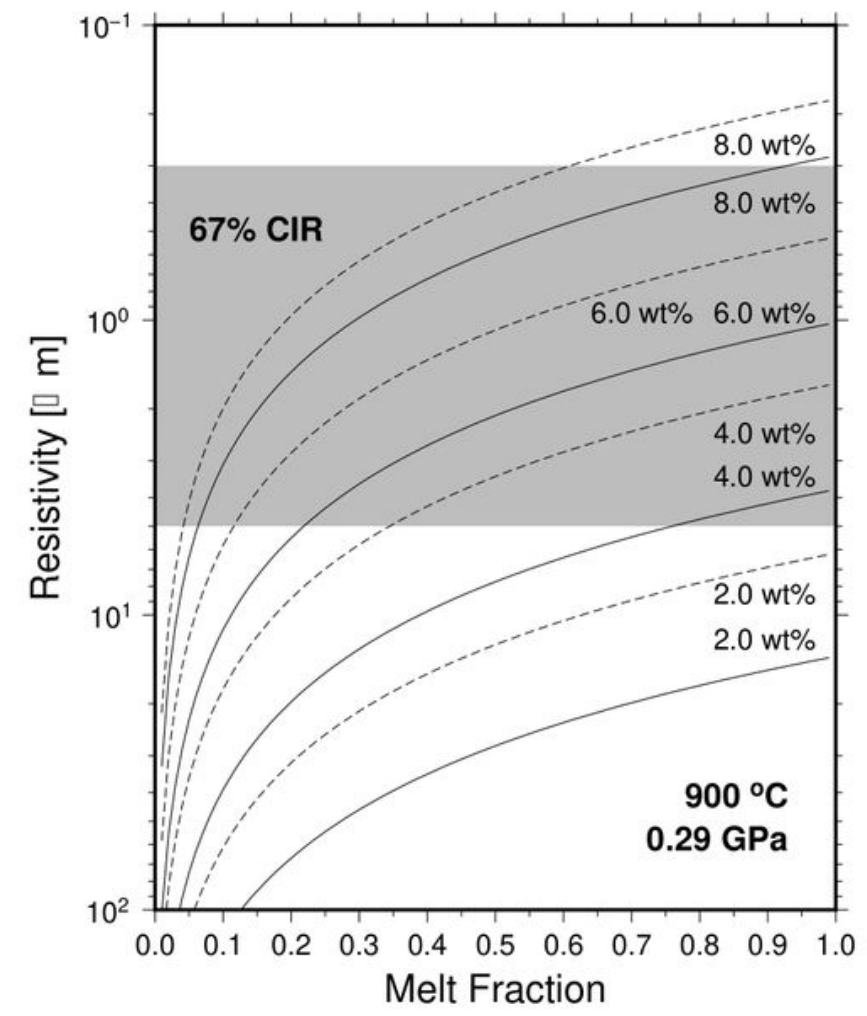

Figure 15

Bulk reistivity (solid line) of andesitic melt and rock complex at $900 \otimes, 0.29 \mathrm{GPa}$ as a function of melt fraction and of water content in the andesitic melt. Melt resistivity calculations from Guo et al. (2017) are shown by the broken line, and from Laumonier et al. (2017) are shown by the solid line. Solid phase 
resistivity is fixed at $500 \Omega \mathrm{m}$ (e.g. rhyolite data of Kariya \& Shankland, 1983). Others are the same as Figure 14.

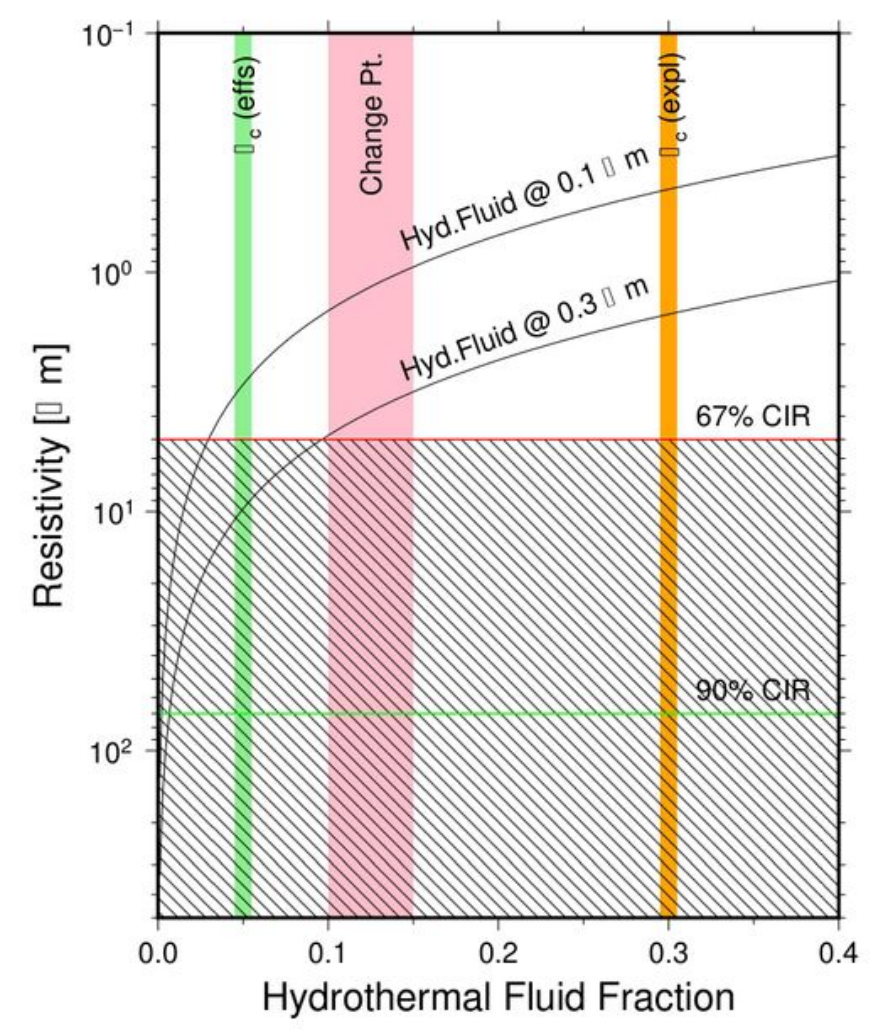

Figure 16

Bulk resistivity of two phases (hydrothermal fluid-rock) as a function of the hydrothermal fluid fraction (solid line). Hydrothermal fluid resistivity is assumed to be 0.1 or $0.3 \Omega \mathrm{m}$. Rock resistivity is fixed at 1000 $\Omega m$ (cf. Figure 14). Green, orange, and pink columns show percolation threshold porosity in effusive and 
explosive eruptions, and change point of permeability-porosity relationship, respectively. Red and green lines show the upper bounds of $67 \%$ and $90 \%$ CIR of the conductor (cf. Figure 11a). Oblique pattern represents likely resistivity range at the Mogi inflation source location, assuming that the upper bound of $\mathrm{CIR}$ of the conductor restricts the lower bound of resistivity at the Mogi inflation source.

\section{Supplementary Files}

This is a list of supplementary files associated with this preprint. Click to download.

- GraphicalAbstract.png

- SupplementalMaterial1.pdf

- SupplementalMaterial2.pdf 